\title{
Research on the Comparison Analyses of Three-Phase Discrete and Integrated LC Filters in Three-Phase PV Inverter
}

\author{
Ying Jiang, ${ }^{1}$ Jianguo Li, ${ }^{1}$ Sanbo Pan, ${ }^{1}$ Xi Zhang, ${ }^{2}$ Peng Hu, ${ }^{1}$ and Haiyan Zhang ${ }^{1}$ \\ ${ }^{1}$ College of Electrical Engineering, Shanghai Dianji University, Shanghai 200240, China \\ ${ }^{2}$ College of Mechanical Engineering, Shanghai Jiao Tong University, Shanghai 200240, China \\ Correspondence should be addressed to Ying Jiang; abjiangying@gmail.com
}

Received 25 January 2013; Revised 25 June 2013; Accepted 11 July 2013

Academic Editor: Keith Emery

Copyright (c) 2013 Ying Jiang et al. This is an open access article distributed under the Creative Commons Attribution License, which permits unrestricted use, distribution, and reproduction in any medium, provided the original work is properly cited.

\begin{abstract}
In three-phase photovoltaic (PV) system, three-phase filter inductors are important part for the output electrical power quality. The comparison analyses of three-phase discrete filter inductors and two kinds of three-phase integrated filter inductors in threephase PV inverter are proposed. Firstly, the three-phase PV inverter operation with discrete filter inductors is analyzed, and the design of discrete filter inductors is given; then operation of the three-phase PV inverter with three-phase integrated five-limb magnetic core filter inductors is analyzed, the design of integrated filter inductors with five-limb magnetic core is given, then the operation of three-phase PV inverter with three-phase integrated three-limb magnetic core filter inductors is analyzed, and the design of integrated filter inductors with three limbs magnetic core is given. The conclusion of comparison between three-phase discrete filter inductors and two kinds of three-phase integrated filter inductors is done; it means that the three-phase discrete filter inductors can achieve better output electrical power quality with lower power density and three-phase integrated filter inductors can achieve higher power density with lower output electrical power quality. Finally, the experiment results are given to compare the volume and filter effect of three kinds of filter inductors in three-phase PV inverter.
\end{abstract}

\section{Introduction}

Photovoltaic (PV) system is becoming increasingly more interesting among all renewable energy [1-4]. Three-phase inverter is wildly used in PV system, and the output electrical power quality is a very important part for the inverter no matter for the grid or the local load [5-7]. In order to achieve better output electrical power quality, the switching harmonics generated by the power inverters must be properly filtered out reaching a compromise between the cost and the weight of the filter and a fulfillment of international standards. Therefore, the PV inverter requires an output lowpass filter to interface with the grid or local load. Nowadays, L filter, LC filter, and LCL filter are wildly used in PV system [8-10]. For L filter, a single inductor L filter is popular and simple to use. Due to causing a long-time response, the system dynamics is poor, but the L filter has the lowest cost among the three filters. The LC filter is very commonly used with most applications, and its output electrical power quality is better than L filter. For LCL filter, it has the best output electrical power quality, but the stability of the system may be compromised by the resonances of the LCL filter, so that several authors have recently studied these issues [11-13]. For example, in [14-16] some control techniques to actively damp the resonances of the filter have been presented.

The demands for PV inverter are not only the good electrical performance but also the high power density, high reliability, and low cost. Among the L filter, LC filter, and LCL filter, most papers pay attention to the electrical performance, and most applications are the single phase PV inverter [17-21]. There are seldom papers of filters about the combination of the electrical performance and the power density, especially in the three-phase PV inverter. However, the three-phase filters are very important factor for the electrical performance, power density, and cost. Therefore, this paper takes the most used LC filter, for example, to research the relation between the output electrical power quality and the volume of three-phase inductors with discrete magnetic core and integrated magnetic core in three-phase PV inverter. 
In this paper, the comparison analyses of three-phase discrete filter inductors and two kinds of three-phase integrated filter inductors of LC filter in three-phase PV inverter are proposed, and the design of three-phase is analyzed including the method how to integrate the three-phase filter inductors into five-limb magnetic core and three-limb magnetic core. The main works are done as below: according to the volume of filter inductor from large to small, the operation of threephase PV inverter with discrete magnetic filter inductor is analyzed firstly, and the design of magnetic core is given; then according to the deduced mathematic expression formula of filter inductor with five-limb magnetic core, the operation of three-phase PV inverter with five-limb magnetic core filter inductor is analyzed, and the design of inductance and magnetic core is given, and then according to the deduced mathematic expression formula of filter inductor with threelimb magnetic core, the operation of three-phase PV inverter with three-limb magnetic core filter inductor is analyzed, and the design of inductance and magnetic core is given. Finally, the experiment results are given to compare the volume and filter effect of three kinds of filter inductors.

\section{The Three-Phase Discrete Filter Inductors in Three-Phase Inverter}

\subsection{The Operational Principle of Three-Phase Discrete Filter} Inductors in Three-Phase LC Filter. The three-phase discrete filter inductors in three-phase inverter are shown in Figure 1. Every filter inductor has its own magnetic core. Therefore, the volumes of inductors are large and the costs are high. Before the analyses, several assumptions are made as follows:

(1) the input voltage source is $V_{\text {in }}$ which come from the PV panel;

(2) switches $Q_{1-6}$ are ideal, diode $D_{1-6}$ is the antiparallel diode of $Q_{1-6}$, and the voltages $V_{a}, V_{b}$, and $V_{c}$ are the output voltage of three bridge arms;

(3) $L_{f 1}, L_{f 2}$, and $L_{f 3}$ are three filter inductors, $C_{1}, C_{2}$, and $C_{3}$ are three filter capacitors, and $V_{L f 1}, V_{L f 2}$, and $V_{L f 3}$ are voltages of three inductors;

(4) $R_{a}, R_{b}$, and $R_{c}$ are three-phase resistance load, $e_{a}, e_{b}$, and $e_{c}$ are three-phase voltage, $i_{a}, i_{b}$, and $i_{c}$ are threephase current, and $e_{o}$ is the voltage of the three-phase load neutral point;

(5) the switch signals can be defined as follows:

$S_{a}= \begin{cases}1 & Q_{1} \text { is turned on, } Q_{4} \text { is turned off; } \\ 0 & Q_{4} \text { is turned on, } Q_{1} \text { is turned off; }\end{cases}$

$S_{b}= \begin{cases}1 & Q_{3} \text { is turned on, } Q_{6} \text { is turned off; } \\ 0 & Q_{6} \text { is turned on, } Q_{3} \text { is turned off; }\end{cases}$

$S_{c}= \begin{cases}1 & Q_{5} \text { is turned on, } Q_{2} \text { is turned off; } \\ 0 & Q_{2} \text { is turned on, } Q_{5} \text { is turned off. }\end{cases}$
According to Figure $1, V_{L f 1}, V_{L f 2}$, and $V_{L f 3}$ can be described as follows:

$$
\begin{aligned}
& V_{L f 1}=V_{a}-e_{a}-e_{o}=L_{f 1} \frac{d i_{a}}{d t}, \\
& V_{L f 2}=V_{b}-e_{b}-e_{o}=L_{f 2} \frac{d i_{b}}{d t}, \\
& V_{L f 3}=V_{c}-e_{c}-e_{o}=L_{f 3} \frac{d i_{c}}{d t} .
\end{aligned}
$$

In three-phase system, the amplitude of current and voltage of every phase are the same, and the $120^{\circ}$ phase difference between every two phase, and then it can be got as

$$
\begin{gathered}
e_{a}+e_{b}+e_{c}=0, \\
i_{a}+i_{b}+i_{c}=0 .
\end{gathered}
$$

According to (2) and (3), neutral point voltage $e_{o}$ can be got as follows:

$$
e_{o}=\frac{V_{a}+V_{b}+V_{c}}{3}
$$

Also, $V_{a}, V_{b}$, and $V_{c}$ can be described as follows:

$$
\begin{aligned}
& V_{a}=S_{a} V_{\text {in }}, \\
& V_{b}=S_{b} V_{\text {in }}, \\
& V_{c}=S_{c} V_{\text {in }} .
\end{aligned}
$$
follows:

Therefore, finally $V_{L f 1}, V_{L f 2}$, and $V_{L f 3}$ can be simplified as

$$
\begin{aligned}
& V_{L f 1}=L_{f 1} \frac{d i_{a}}{d t}=\frac{2 S_{a}-S_{b}-S_{c}}{3} V_{\text {in }}-e_{a}, \\
& V_{L f 2}=L_{f 2} \frac{d i_{b}}{d t}=\frac{2 S_{b}-S_{a}-S_{c}}{3} V_{\text {in }}-e_{b}, \\
& V_{L f 3}=L_{f 3} \frac{d i_{c}}{d t}=\frac{2 S_{c}-S_{a}-S_{b}}{3} V_{\text {in }}-e_{c} .
\end{aligned}
$$

The above formula is the basic expression of threephase discrete inductors. The main functions of three-phase inductors are to reduce the harmonic by limiting the ripple current.

2.2. The SPWM Control Method of Three-Phase Inverter. In this paper, the sine-wave pulse-width modulation (SPWM) control method is adopted. The SPWM control method is widely used in the inverter due to its simple and easy realizing, and it is has been a mature technology. Though there are some advantaged control methods such as space voltage vector pulse-width modulation (SVPWM), the SPWM control method is enough to verify the basic function of LC filter, and the SPWM control method is shown in Figure 2. Through the comparison between the high frequency triangular wave signal $u_{o}$ and three-phase line frequency sine wave signal $u_{g a}$, $u_{g b}$, and $u_{g c}$, the control signals $u_{\mathrm{Q} 1-6}$ for switches $Q_{1-6}$ are got. 


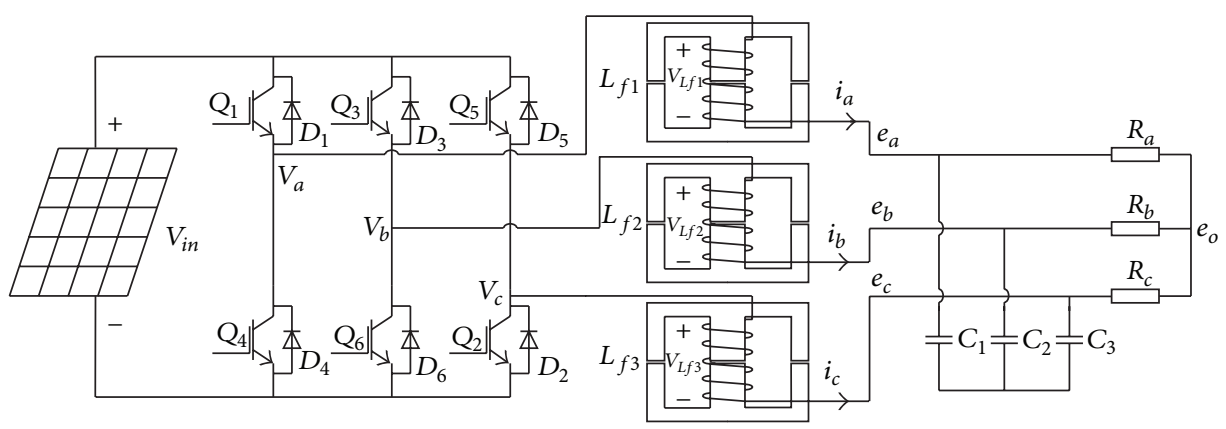

FIgURE 1: The three-phase discrete filter inductors in three-phase inverter.

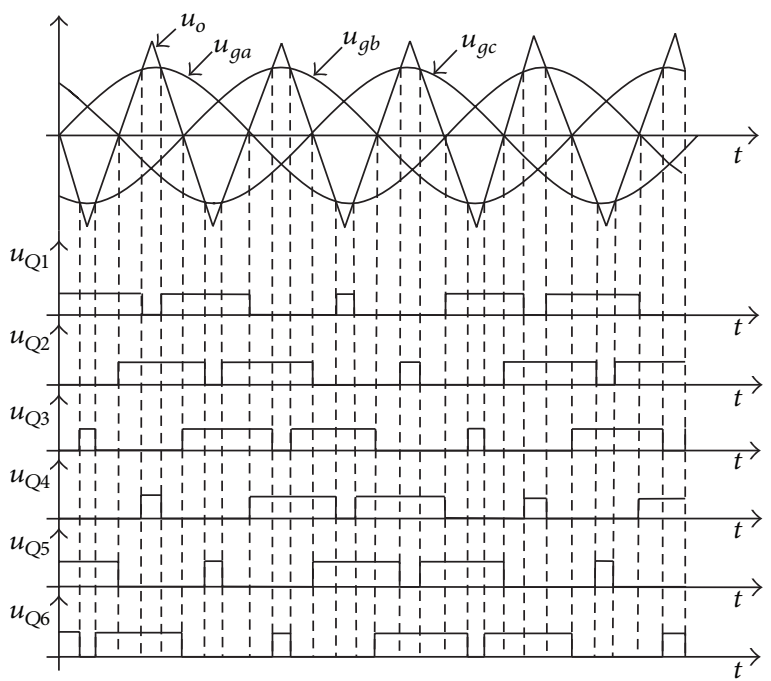

FIgURE 2: The three-phase SPWM control method.

\subsection{The Ripple Current of Three-Phase Discrete Filter Induc-} tors. In order to get better output electrical power quality, smaller ripple current of inductor should be achieved. Besides, the ripple current also decides the volume and the value of inductor. Therefore, the ripple current of filter inductor is an important parameter.

According to (6), take the ripple current of $L_{f 1}$, for example, to analyze, it can be got that

$$
V_{L f 1}=L_{f 1} \frac{\Delta i_{a}}{\Delta t}=\frac{2 S_{a}-S_{b}-S_{c}}{3} V_{d c}-e_{a}
$$

$\Delta i_{a}$ is the ripple current of $L_{f 1}$, and it can be got as follows:

$$
\Delta i_{a}=\left(\frac{2 S_{a}-S_{b}-S_{c}}{3} V_{d c}-e_{a}\right) \frac{D_{\mathrm{on}} T}{L_{f 1}},
$$

where $T$ is cycle and $D_{\text {on }}$ is duty cycle when the ripple current increases. Since the current ripple directly decides the harmonic, the ripple current $\Delta i_{a}$ is always selected as the (10-20)\% of the max value of $i_{a}$. Based on the selected ripple current $\Delta i_{a}$, the value of inductor $L_{f 1}$ can also be selected. Since the three-phase inductors have three discrete magnetic cores, every inductor does not affect each other; then the demanded filter effect can be achieved and the design of inductor is not very complicated. The three-phase discrete inductors can achieve wide application, but the volume, weight, and cost are their disadvantage.

2.4. The Max Flux Density of Discrete Filter Inductors. In order to design the magnetic core of the discrete filter inductor, the flux density should be analyzed. Take the $L_{f 1}$ for example, to analyze, and the other $L_{f_{2}}$ and $L_{f 3}$ have the same analyzed method. The $L_{f 1}$ filter inductor with magnetic core is shown in Figure 3(a). $\phi_{a}$ is the flux generated by $L_{f 1}$ winding; $\mathfrak{R}_{01}$ are the magnetic resistance of the middle limb, and $\mathfrak{R}_{02}$ are the magnetic resistance of the other two limbs; $N_{L f 1}$ is the number of turns of $L_{f 1}$ winding. According to the magnetic circuit which is shown in Figure 3(b), $\phi_{a}$ can be described as follows:

$$
\phi_{a}=\frac{N_{L f 1} i_{a}}{\mathfrak{R}_{01}+\mathfrak{R}_{02} / / \mathfrak{R}_{02}}=\frac{2 N_{L f 1} i_{a}}{2 \mathfrak{R}_{01}+\mathfrak{R}_{02}} .
$$

Therefore, the voltage of inductors $V_{L f 1}$ can be described as follows:

$$
V_{L f 1}=N_{L f 1} \frac{d \phi_{a}}{d t}
$$

According to (10), $V_{L f 1}$ can be described as follows:

$$
V_{L f 1}=L_{f 1} \frac{d i_{a}}{d t}
$$

where $L_{f 1}$ is self-inductor and can be described as follows:

$$
L_{f 1}=\frac{2 N_{L f 1}^{2}}{2 \mathfrak{R}_{01}+\mathfrak{R}_{02}} .
$$

The magnetic resistance can be got as follows:

$$
\mathfrak{R}_{0 i}=\frac{l_{g i}}{\mu_{0} A_{i}}, \quad i=1,2,
$$

where $l_{g i}$ and $A_{i}$ are, respectively, the air gap and cross section area of $\mathfrak{R}_{0 i}, \mu_{0}$ is air permeability, and for the EE type magnetic core, the cross section area of middle limb is two times of that of the other two limbs. Then, when make the air gap of three limbs are the same, it can be got that $2 \mathfrak{R}_{01}=\mathfrak{R}_{02}$. 


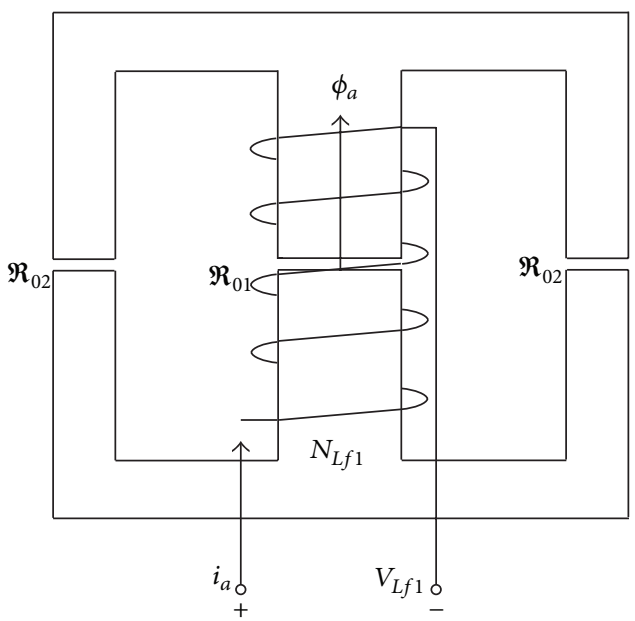

(a)

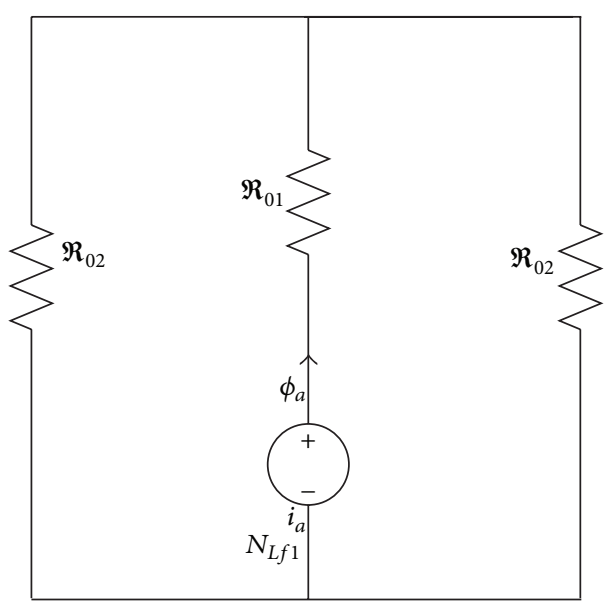

(b)

Figure 3: Three-phase discrete inductor: (a) magnetic core, (b) magnetic circuit.

The three-phase current $i_{a}$ can be described as follows:

$$
i_{a}=\sqrt{2} I_{m} \sin (\omega t)
$$

where $I_{m}$ is the effective value of current.

Therefore, when $\phi_{a}$ achieves its max value $\phi_{a \max }$, the max flux density $B_{a \max }$ of middle limb can be described as follows:

$$
B_{a \max }=\frac{\phi_{a \max }}{A_{2}}=\frac{L_{f 1} \sqrt{2} I_{m}}{A_{2} N_{L f 1}}=\frac{\sqrt{2} I_{m} N_{L f 1} u_{0}}{l_{g 2}} .
$$

Then, the magnetic core can be selected according to the $B_{a \max }$

\section{The Three-Phase Integrated Filter Inductors with One Five-Limb Magnetic Core in Three-Phase Inverter}

The three-phase integrated filter inductors with one five-limb magnetic core in three-phase inverter are shown in Figure 4. The three filter inductors have one magnetic core with five limbs, and the magnetic core consists of two EE magnetic cores. The three filter inductors are on the middle three limbs, and the cross section area of three middle limbs is twice than that of the other two limbs.

3.1. The Expression of Three-Phase Integrated Filter Inductors with Five Magnetic Limbs. The three-phase integrated filter inductors with five magnetic limbs are shown in Figure 5(a). $\phi_{a}, \phi_{b}$, and $\phi_{c}$ are, respectively, the fluxes generated by $L_{f 1}$ winding, $L_{f 2}$ winding, and $L_{f 3}$ winding; $\mathfrak{R}_{01}$ are the magnetic resistance of three middle limbs, and $\mathfrak{R}_{02}$ are the magnetic resistance of the other two limbs; $N_{L f 1}, N_{L f 2}$, and $N_{L f 3}$ are, respectively, the number of turns of $L_{f 1}$ winding, $L_{f 2}$ winding, and $L_{f 3}$ winding. According to the magnetic circuit which is shown in Figure 5(b), $\phi_{a}$ is the flux generated by $L_{f 1}$ winding, $\phi_{a b}$ is the flux generated by $L_{f 1}$ winding flows through $L_{f 2}$ winding, and $\phi_{a c}$ is the flux generated by
$L_{f 1}$ winding flows through $L_{f 3}$ winding, and they can be described as follows:

$$
\begin{gathered}
\phi_{a}=\frac{N_{L f 1} i_{a}}{\mathfrak{R}_{01}+\mathfrak{R}_{01} / / \mathfrak{R}_{01} / / \mathfrak{R}_{02} / / \mathfrak{R}_{02}}=\frac{2 N_{L f 1} i_{a}\left(\mathfrak{R}_{01}+\mathfrak{R}_{02}\right)}{2 \mathfrak{R}_{01}^{2}+3 \mathfrak{R}_{01} \mathfrak{R}_{02}}, \\
\phi_{a b}=\phi_{a c}=\frac{2 N_{L f 1} i_{a}\left(\mathfrak{R}_{01}+\mathfrak{R}_{02}\right)}{2 \mathfrak{R}_{01}^{2}+3 \mathfrak{R}_{01} \mathfrak{R}_{02}} \frac{\mathfrak{R}_{02}}{2\left(\mathfrak{R}_{01}+\mathfrak{R}_{02}\right)} \\
=\frac{N_{L f 1} i_{a} \mathfrak{R}_{02}}{2 \mathfrak{R}_{01}^{2}+3 \mathfrak{R}_{01} \mathfrak{R}_{02}}
\end{gathered}
$$

$\phi_{b}$ is the flux generated by $L_{f 2}$ winding, $\phi_{b a}$ is the flux generated by $L_{f 2}$ winding flows through $L_{f 1}$ winding, and $\phi_{b c}$ is the flux generated by $L_{f 2}$ winding flows through $L_{f 3}$ winding, and they can be described as follows:

$$
\begin{aligned}
\phi_{b} & =\frac{N_{L f 2} i_{b}}{\mathfrak{R}_{01}+\mathfrak{R}_{01} / / \mathfrak{R}_{01} / / \mathfrak{R}_{02} / / \mathfrak{R}_{02}} \\
& =\frac{2 N_{L f 2} i_{b}\left(\mathfrak{R}_{01}+\mathfrak{R}_{02}\right)}{2 \mathfrak{R}_{01}^{2}+3 \mathfrak{R}_{01} \mathfrak{R}_{02}}, \\
\phi_{b a} & =\phi_{b c}=\frac{2 N_{L f 2} i_{b}\left(\mathfrak{R}_{01}+\mathfrak{R}_{02}\right)}{2 \mathfrak{R}_{01}^{2}+3 \mathfrak{R}_{01} \mathfrak{R}_{02}} \frac{\mathfrak{R}_{02}}{2\left(\mathfrak{R}_{01}+\mathfrak{R}_{02}\right)} \\
& =\frac{N_{L f 2} i_{b} \mathfrak{R}_{02}}{2 \mathfrak{R}_{01}^{2}+3 \mathfrak{R}_{01} \mathfrak{R}_{02}}
\end{aligned}
$$

$\phi_{c}$ is the flux generated by $L_{f 3}$ winding, $\phi_{c a}$ is the flux generated by $L_{f 3}$ winding flows through $L_{f 1}$ winding, and $\phi_{c b}$ is the flux generated by $L_{f 3}$ winding flows through $L_{f 2}$ winding, and they can be described as follows:

$$
\begin{aligned}
\phi_{c} & =\frac{N_{L f 3} i_{c}}{\mathfrak{R}_{01}+\mathfrak{R}_{01} / / \mathfrak{R}_{01} / / \mathfrak{R}_{02} / / \mathfrak{R}_{02}} \\
& =\frac{2 N_{L f 3} i_{c}\left(\mathfrak{R}_{01}+\mathfrak{R}_{02}\right)}{2 \mathfrak{R}_{01}^{2}+3 \mathfrak{R}_{01} \mathfrak{R}_{02}},
\end{aligned}
$$




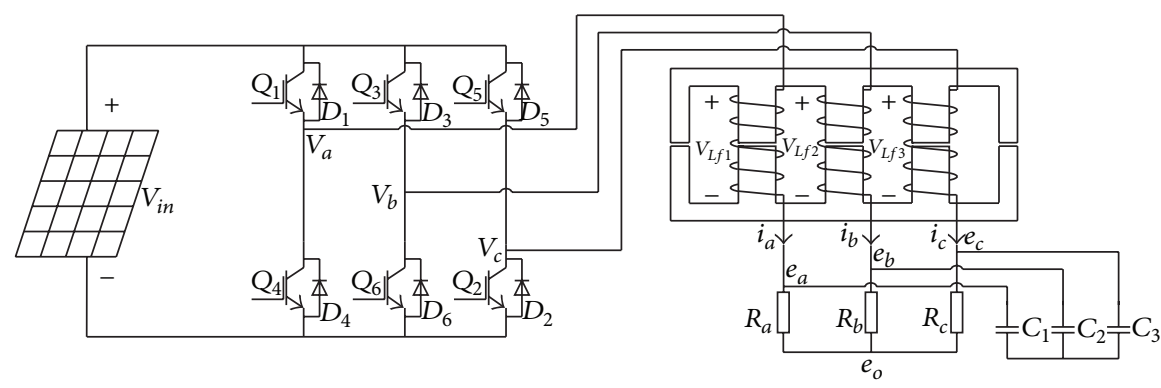

FIgURE 4: The three-phase integrated filter inductors with five magnetic limbs in three-phase inverter.

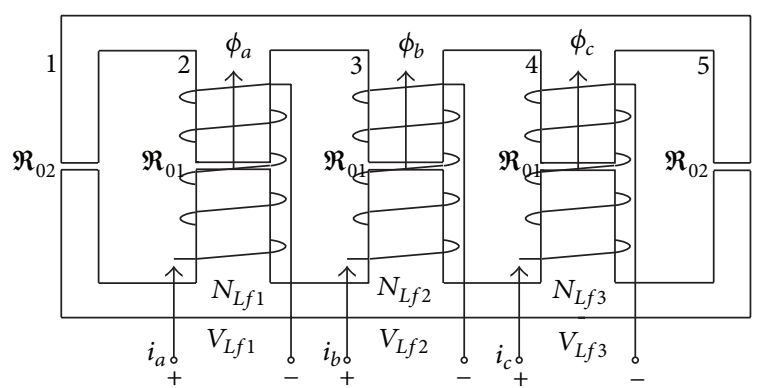

(a)

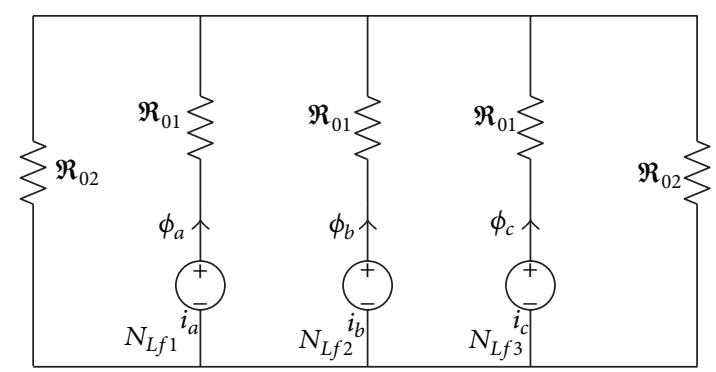

(b)

FIgURE 5: Three-phase integrated inductors with five magnetic limbs: (a) three-phase magnetic core with five limbs, (b) magnetic circuit.

$$
\begin{aligned}
\phi_{c a} & =\phi_{c b}=\frac{2 N_{L f 3} i_{c}\left(\mathfrak{R}_{01}+\mathfrak{R}_{02}\right)}{2 \mathfrak{R}_{01}^{2}+3 \mathfrak{R}_{01} \mathfrak{R}_{02}} \frac{\mathfrak{R}_{02}}{2\left(\mathfrak{R}_{01}+\mathfrak{R}_{02}\right)} \\
& =\frac{N_{L f 3} i_{c} \mathfrak{R}_{02}}{2 \mathfrak{R}_{01}^{2}+3 \mathfrak{R}_{01} \mathfrak{R}_{02}} .
\end{aligned}
$$

Every total flux of inductor winding consists of three parts: one is the self-flux and the others are generated by the other two inductor windings. Therefore, the voltages of inductors $V_{L f 1}, V_{L f 2}$, and $V_{L f 3}$ can be described as follows:

$$
\begin{aligned}
& V_{L f 1}=N_{L f 1} \frac{d}{d t}\left(\phi_{a}+\phi_{b a}+\phi_{c a}\right), \\
& V_{L f 2}=N_{L f 2} \frac{d}{d t}\left(\phi_{b}+\phi_{a b}+\phi_{c b}\right), \\
& V_{L f 3}=N_{L f 3} \frac{d}{d t}\left(\phi_{c}+\phi_{a c}+\phi_{b c}\right) .
\end{aligned}
$$

According to (16), (17), (18), and (19), $V_{L f 1}, V_{L f 2}$, and $V_{L f 3}$ also can be described as follows:

$$
\left(\begin{array}{c}
V_{L f 1} \\
V_{L f 2} \\
V_{L f 3}
\end{array}\right)=\left(\begin{array}{lll}
L_{f 1} & M_{a b} & M_{a c} \\
M_{a b} & L_{f 2} & M_{b c} \\
M_{a c} & M_{b c} & L_{f 3}
\end{array}\right)\left(\begin{array}{c}
\frac{d i_{a}}{d t} \\
\frac{d i_{b}}{d t} \\
\frac{d i_{c}}{d t}
\end{array}\right)
$$

where $L_{f 1}, L_{f 2}$, and $L_{f 3}$ are self-inductor and can be described as follows:

$$
\begin{aligned}
& L_{f 1}=\frac{2 N_{L f 1}^{2}\left(\mathfrak{R}_{01}+\mathfrak{R}_{02}\right)}{2 \mathfrak{R}_{01}^{2}+3 \mathfrak{R}_{01} \mathfrak{R}_{02}}, \\
& L_{f 2}=\frac{2 N_{L f 2}^{2}\left(\mathfrak{R}_{01}+\mathfrak{R}_{02}\right)}{2 \mathfrak{R}_{01}^{2}+3 \mathfrak{R}_{01} \mathfrak{R}_{02}}, \\
& L_{f 3}=\frac{2 N_{L f 3}^{2}\left(\mathfrak{R}_{01}+\mathfrak{R}_{02}\right)}{2 \mathfrak{R}_{01}^{2}+3 \mathfrak{R}_{01} \mathfrak{R}_{02}} .
\end{aligned}
$$

$M_{a b}, M_{a c}$, and $M_{b c}$ are mutual inductance and can be described as follows:

$$
\begin{gathered}
M_{a b}=\frac{N_{L f 1} N_{L f 2} \mathfrak{R}_{02}}{2 \mathfrak{R}_{01}^{2}+3 \mathfrak{R}_{01} \mathfrak{R}_{02}}, \\
M_{a c}=\frac{N_{L f 1} N_{L f 3} \mathfrak{R}_{02}}{2 \mathfrak{R}_{01}^{2}+3 \mathfrak{R}_{01} \mathfrak{R}_{02}}, \\
M_{b c}=\frac{N_{L f 2} N_{L f 3} \mathfrak{R}_{02}}{2 \mathfrak{R}_{01}^{2}+3 \mathfrak{R}_{01} \mathfrak{R}_{02}} .
\end{gathered}
$$

In order to make the three-phases balanced, the number of turns of three-phase inductor is the same; it means that $N_{L f 1}=N_{L f 2}=N_{L f 3}$. Therefore, it can be got that $L_{f 1}=$ $L_{f 2}=L_{f 3}=L_{f}$, and $M_{a b}=M_{a c}=M_{b c}=M$. Then, finally 
the expression of three-phase integrated inductors with five magnetic limbs can be described as follows:

$$
\left(\begin{array}{c}
V_{L f 1} \\
V_{L f 2} \\
V_{L f 3}
\end{array}\right)=\left(\begin{array}{ccc}
L_{f} & M & M \\
M & L_{f} & M \\
M & M & L_{f}
\end{array}\right)\left(\begin{array}{c}
\frac{d i_{a}}{d t} \\
\frac{d i_{b}}{d t} \\
\frac{d i_{c}}{d t}
\end{array}\right)
$$

Based on (23), it can be got that the three-phase inductors couple with each other, and then the current ripple can be analyzed.

\subsection{The Ripple Current of Three-Phase Integrated Filter} Inductors with Five-Limb Magnetic Core. In order to achieve the demanded filter effect of three-phase integrated filter inductors with five magnetic limbs, the current ripples should be analyzed. According to (23), $V_{L f 1}, V_{L f 2}$, and $V_{L f 3}$ can be described as follows:

$$
\begin{aligned}
& V_{L f 1}=V_{a}-e_{a}-e_{o}=L_{f 1} \frac{d i_{a}}{d t}+M \frac{d i_{b}}{d t}+M \frac{d i_{c}}{d t}, \\
& V_{L f 2}=V_{b}-e_{b}-e_{o}=L_{f 2} \frac{d i_{b}}{d t}+M \frac{d i_{a}}{d t}+M \frac{d i_{c}}{d t}, \\
& V_{L f 3}=V_{c}-e_{c}-e_{o}=L_{f 3} \frac{d i_{c}}{d t}+M \frac{d i_{b}}{d t}+M \frac{d i_{a}}{d t} .
\end{aligned}
$$

Furthermore, it can be simplified as follows:

$$
\begin{aligned}
& V_{L f 1}=\frac{2 S_{a}-S_{b}-S_{c}}{3} V_{\text {in }}-e_{a}=L_{f 1} \frac{d i_{a}}{d t}+M \frac{d i_{b}}{d t}+M \frac{d i_{c}}{d t}, \\
& V_{L f 2}=\frac{2 S_{b}-S_{a}-S_{c}}{3} V_{\text {in }}-e_{b}=L_{f 2} \frac{d i_{b}}{d t}+M \frac{d i_{a}}{d t}+M \frac{d i_{c}}{d t}, \\
& V_{L f 3}=\frac{2 S_{c}-S_{a}-S_{b}}{3} V_{\text {in }}-e_{c}=L_{f 3} \frac{d i_{c}}{d t}+M \frac{d i_{b}}{d t}+M \frac{d i_{a}}{d t} .
\end{aligned}
$$

Take the ripple current $\Delta i_{a}$ of $L_{f 1}$, for example, to analyze, it can be got that

$$
\begin{aligned}
\Delta i_{a}= & \left(\frac{2 S_{a}-S_{b}-S_{c}}{3} V_{d c}-e_{a}-M \frac{d i_{b}}{d t}-M \frac{d i_{c}}{d t}\right) \\
& \times \frac{D_{\mathrm{on}} T}{L_{f 1}} .
\end{aligned}
$$

It can be got that the ripple current $\Delta i_{a}$ are influenced by switching signals $S_{a}, S_{b}$, and $S_{c}$ which are decided by control method, and the mutual inductors and currents of the other two phases. Since the ripple currents are coupled with each other, it is complicated to design the ideal value of ripple current for fulfilling the demand of harmonic. In order to reduce the influence by other two phases, the mutual inductors can be eliminated. According to (22), the mutual inductor is described as follows:

$$
M=\frac{N_{L f}^{2} \mathfrak{R}_{02}}{2 \mathfrak{R}_{01}^{2}+3 \mathfrak{R}_{01} \mathfrak{R}_{02}} .
$$

The magnetic resistance can be got as follows:

$$
\mathfrak{R}_{0 i}=\frac{l_{g i}}{\mu_{0} A_{i}}, \quad i=1,2,
$$

where $l_{g i}$ and $A_{i}$ are, respectively, the air gap and cross section area of $\mathfrak{R}_{0 i}$ and $\mu_{0}$ is air permeability.

In order to reduce the mutual inductor, according to (27), when the magnetic resistance $\mathfrak{R}_{02}$ is zero, the mutual inductor $M$ can be eliminated. Therefore, the air gap $l_{g 2}$ of $\mathfrak{R}_{02}$ can be adjusted to zero to reduce the mutual inductor. Then, (26) can be simplified as follows:

$$
\begin{aligned}
\Delta i_{a}= & \left(\frac{2 S_{a}-S_{b}-S_{c}}{3} V_{d c}-e_{a}\right) \\
& \times \frac{D_{\mathrm{on}} T}{L_{f 1}} .
\end{aligned}
$$

Based on (22), it can be got that the ripple currents of three-phase integrated filter inductors with five limbs are the same as those of three-phase discrete filter inductors. It means that the two kinds of three-phase inductors have the same filter effect, but the volume of integrated filter inductors with five limbs is less than that of discrete filter inductors.

\subsection{The Max Flux Density of Integrated Filter Inductors with} Five Magnetic Limbs. In order to design the magnetic core of the three-phase integrated filter inductors with five limbs, the flux density of every limb should be analyzed. There are five limbs of the magnetic core of integrated filter inductor, and the middle three limbs have the windings of three-phase filter inductors. In order to reduce the mutual inductor, the middle three limbs have the same air gaps; the other two limbs have no air gaps; it means that the middle three limbs have the magnetic resistances and the other two limbs have no magnetic resistances. Therefore, the fluxes generated by the three inductor windings of middle three limbs all flow through the other two limbs and donot flow through each other. Taking the flux $\phi_{a}$ generated by $L_{f 1}$ winding of second limb for example, $\phi_{a}$ can be got as follows:

$$
\phi_{a}=\frac{L_{f 1} i_{a}}{N_{L f 1}} .
$$

Since the magnetic resistance $\mathfrak{R}_{02}$ is zero, and according to (28), then $L_{f 1}$ can be got as follows:

$$
\begin{aligned}
L_{f 1} & =\frac{2 N_{L f 1}^{2}\left(\mathfrak{R}_{01}+\mathfrak{R}_{02}\right)}{2 \mathfrak{R}_{01}^{2}+3 \mathfrak{R}_{01} \mathfrak{R}_{02}} \\
& =\frac{N_{L f 1}^{2}}{\mathfrak{R}_{01}}=\frac{N_{L f 1}^{2} u_{0} A_{2}}{l_{g 2}} .
\end{aligned}
$$



follows:

The three-phase current $i_{a}, i_{b}$, and $i_{c}$ can be described as

$$
\begin{gathered}
i_{a}=\sqrt{2} I_{m} \sin (\omega t), \\
i_{b}=\sqrt{2} I_{m} \sin \left(\omega t+\frac{2 \pi}{3}\right), \\
i_{c}=\sqrt{2} I_{m} \sin \left(\omega t-\frac{2 \pi}{3}\right),
\end{gathered}
$$

where $I_{m}$ is the effective value of current.

Therefore, when $\phi_{a}$ achieves its max value $\phi_{a \max }$, the max flux density $B_{2 \max }$ of second limb can be described as follows:

$$
\begin{aligned}
B_{2 \max } & =\frac{\phi_{a \max }}{A_{2}} \\
& =\frac{L_{f 1} \sqrt{2} I_{m}}{A_{2} N_{L f 1}}=\frac{\sqrt{2} I_{m} N_{L f 1} u_{0}}{l_{g 2}} .
\end{aligned}
$$

Also, the max flux densities $B_{3 \max }$ and $B_{4 \max }$ of the third and fourth limbs can be described as follows:

$$
\begin{aligned}
B_{3 \max } & =\frac{\sqrt{2} I_{m} N_{L f 2} u_{0}}{l_{g 3}}, \\
B_{4 \max } & =\frac{\sqrt{2} I_{m} N_{L f 3} u_{0}}{l_{g 4}} .
\end{aligned}
$$

The fluxes of the first and fifth limbs consist of three parts of fluxes which are generated by the middle three limbs. Taking the flux $\phi_{1}$ of the first limb, for example, $\phi_{1}$ consists of $\phi_{a 1}$ generated by $L_{f 1}$ winding, $\phi_{b 1}$ generated by $L_{f 2}$ winding, and $\phi_{c 1}$ generated by $L_{f 3}$ winding. $\phi_{a 1}, \phi_{b 1}$, and $\phi_{c 1}$ can be described as follows:

$$
\begin{aligned}
& \phi_{a 1}=\frac{N_{L f 1} i_{a} \mathfrak{R}_{01}}{2 \mathfrak{R}_{01}^{2}+3 \mathfrak{R}_{01} \mathfrak{R}_{02}}, \\
& \phi_{b 1}=\frac{N_{L f 2} i_{b} \mathfrak{R}_{01}}{2 \mathfrak{R}_{01}^{2}+3 \mathfrak{R}_{01} \mathfrak{R}_{02}}, \\
& \phi_{c 1}=\frac{N_{L f 3} i_{c} \mathfrak{R}_{01}}{2 \mathfrak{R}_{01}^{2}+3 \mathfrak{R}_{01} \mathfrak{R}_{02}} .
\end{aligned}
$$

Therefore, $\phi_{1}$ can be got as follows:

$$
\begin{aligned}
\phi_{1} & =\phi_{a 1}+\phi_{b 1}+\phi_{c 1} \\
& =\frac{N_{L f} \mathfrak{R}_{01}\left(i_{a}+i_{b}+i_{c}\right)}{2 \mathfrak{R}_{01}^{2}+3 \mathfrak{R}_{01} \mathfrak{R}_{02}} .
\end{aligned}
$$

Since in three-phase system, $i_{a}+i_{b}+i_{c}=0$. Therefore, the total flux $\phi_{1}$ is zero. The main functions of the first and fifth limbs are to adjust the mutual inductors.

\section{The Integrated Three-Phase Filter Inductors with Five-Limb Magnetic Core in Three-Phase Inverter}

In order to further decrease the volume of three-phase filter inductor, the five magnetic limbs can be simplified to three magnetic limbs which are shown in Figure 6. In Figure 6, one EE magnetic core is adopted, and the cross section area of middle limb is twice than that of the other two limbs. Since, compared with the above two kinds of three-phase filter inductors, this kind of three-phase integrated filter inductor can achieve the least volume.

4.1. The Expression of Three-Phase Integrated Filter Inductors with Three Magnetic Limbs. The integrated three-phase filter inductors with three-limb magnetic core are shown in Figure $7(\mathrm{a}) . \phi_{a}, \phi_{b}$, and $\phi_{c}$ are, respectively, the fluxes generated by $L_{f 1}$ winding, $L_{f 2}$ winding, and $L_{f 3}$ winding; $\mathfrak{R}_{1}, \mathfrak{R}_{2}$, and $\mathfrak{R}_{3}$ are, respectively, the magnetic resistance of three limbs. According to the magnetic circuit which is shown in Figure 7(b), $\phi_{a}$ is the flux generated by $L_{f 1}$ winding, $\phi_{a b}$ is the flux generated by $L_{f 1}$ winding flows through $L_{f 2}$ winding, and $\phi_{a c}$ is the flux generated by $L_{f 1}$ winding flows through $L_{f 3}$ winding, and they can be described as follows:

$$
\begin{gathered}
\phi_{a}=\frac{N_{L f 1} i_{a}}{\mathfrak{R}_{1}+\mathfrak{R}_{2} / / \mathfrak{R}_{3}}=\frac{N_{L f 1} i_{a}\left(\mathfrak{R}_{3}+\mathfrak{R}_{2}\right)}{\mathfrak{R}_{1} \mathfrak{R}_{2}+\mathfrak{R}_{1} \mathfrak{R}_{3}+\mathfrak{R}_{2} \mathfrak{R}_{3}}, \\
\phi_{a b}=\frac{N_{L f 1} i_{a}\left(\mathfrak{R}_{3}+\mathfrak{R}_{2}\right)}{\mathfrak{R}_{1} \mathfrak{R}_{2}+\mathfrak{R}_{1} \mathfrak{R}_{3}+\mathfrak{R}_{2} \mathfrak{R}_{3}} \frac{\mathfrak{R}_{3}}{\mathfrak{R}_{3}+\mathfrak{R}_{2}} \\
=\frac{N_{L f 1} i_{a} \mathfrak{R}_{3}}{\mathfrak{R}_{1} \mathfrak{R}_{2}+\mathfrak{R}_{1} \mathfrak{R}_{3}+\mathfrak{R}_{2} \mathfrak{R}_{3}}, \\
\phi_{a c}=\frac{N_{L f 1} i_{a}\left(\mathfrak{R}_{3}+\mathfrak{R}_{2}\right)}{\mathfrak{R}_{1} \mathfrak{R}_{2}+\mathfrak{R}_{1} \mathfrak{R}_{3}+\mathfrak{R}_{2} \mathfrak{R}_{3}} \frac{\mathfrak{R}_{2}}{\mathfrak{R}_{3}+\mathfrak{R}_{2}} \\
=\frac{N_{L f 1} i_{a} \mathfrak{R}_{2}}{\mathfrak{R}_{1} \mathfrak{R}_{2}+\mathfrak{R}_{1} \mathfrak{R}_{3}+\mathfrak{R}_{2} \mathfrak{R}_{3}} .
\end{gathered}
$$

Also, $\phi_{b}$ is the flux generated by $L_{f 2}$ winding, $\phi_{b a}$ is the flux generated by $L_{f 2}$ winding flows through $L_{f 1}$ winding, and $\phi_{b c}$ is the flux generated by $L_{f 2}$ winding flows through $L_{f 3}$ winding, and they can be described as follows:

$$
\begin{gathered}
\phi_{b}=\frac{N_{L f 2} i_{L f 2}}{\mathfrak{R}_{2}+\mathfrak{R}_{1} / / \mathfrak{R}_{3}}=\frac{N_{L f 2} i_{L f 2}\left(\mathfrak{R}_{1}+\mathfrak{R}_{3}\right)}{\mathfrak{R}_{1} \mathfrak{R}_{2}+\mathfrak{R}_{1} \mathfrak{R}_{3}+\mathfrak{R}_{2} \mathfrak{R}_{3}}, \\
\phi_{b a}=\frac{N_{L f 2} i_{b}\left(\mathfrak{R}_{1}+\mathfrak{R}_{3}\right)}{\mathfrak{R}_{1} \mathfrak{R}_{2}+\mathfrak{R}_{1} \mathfrak{R}_{3}+\mathfrak{R}_{2} \mathfrak{R}_{3}} \frac{\mathfrak{R}_{3}}{\mathfrak{R}_{1}+\mathfrak{R}_{3}} \\
=\frac{N_{L f 2} i_{b} \mathfrak{R}_{3}}{\mathfrak{R}_{1} \mathfrak{R}_{2}+\mathfrak{R}_{1} \mathfrak{R}_{3}+\mathfrak{R}_{2} \mathfrak{R}_{3}}, \\
\phi_{b c}=\frac{N_{L f 2} i_{b}\left(\mathfrak{R}_{1}+\mathfrak{R}_{3}\right)}{\mathfrak{R}_{1} \mathfrak{R}_{2}+\mathfrak{R}_{1} \mathfrak{R}_{3}+\mathfrak{R}_{2} \mathfrak{R}_{3}} \frac{\mathfrak{R}_{2}}{\mathfrak{R}_{1}+\mathfrak{R}_{3}} \\
=\frac{N_{L f 2} i_{b} \mathfrak{R}_{1}}{\mathfrak{R}_{1} \mathfrak{R}_{2}+\mathfrak{R}_{1} \mathfrak{R}_{3}+\mathfrak{R}_{2} \mathfrak{R}_{3}}
\end{gathered}
$$

$\phi_{c}$ is the flux generated by $L_{f 3}$ winding, $\phi_{c a}$ is the flux generated by $L_{f 3}$ winding flows through $L_{f 1}$ winding, and 


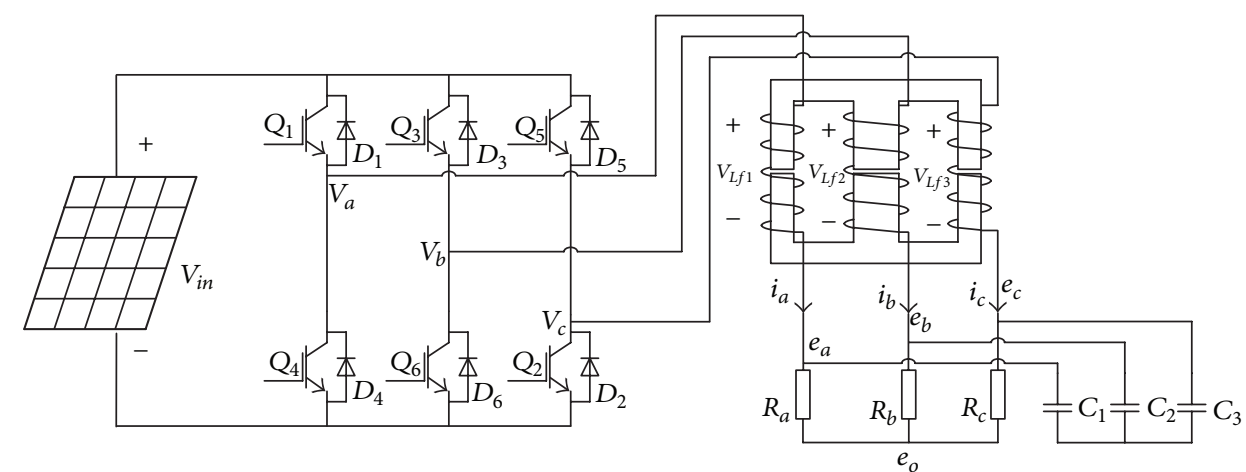

FIGURE 6: The three-phase integrated filter inductors with three magnetic limbs in three-phase inverter.

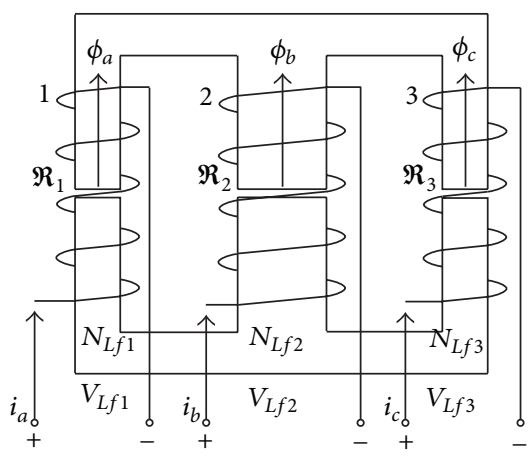

(a)

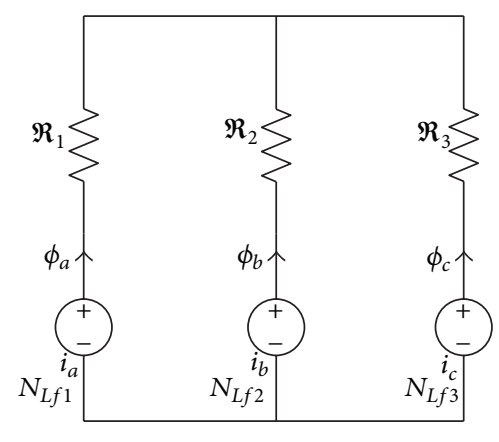

(b)

FIGURE 7: Three-phase integrated inductors with five magnetic limbs: (a) three-phase magnetic core with five limbs, (b) magnetic circuit.

$\phi_{c b}$ is the flux generated by $L_{f 3}$ winding flows through $L_{f 2}$ winding, and they can be described as follows:

$$
\begin{gathered}
\phi_{c}=\frac{N_{L f 3} i_{c}}{\mathfrak{R}_{3}+\mathfrak{R}_{1} / / \mathfrak{R}_{2}}=\frac{N_{L f 2} i_{c}\left(\Re_{1}+\mathfrak{R}_{2}\right)}{\mathfrak{R}_{1} \mathfrak{R}_{2}+\mathfrak{R}_{1} \mathfrak{R}_{3}+\mathfrak{R}_{2} \mathfrak{R}_{3}}, \\
\phi_{c a}=\frac{N_{L f 3} i_{c}\left(\mathfrak{R}_{1}+\mathfrak{R}_{2}\right)}{\mathfrak{R}_{1} \mathfrak{R}_{2}+\mathfrak{R}_{1} \mathfrak{R}_{3}+\mathfrak{R}_{2} \mathfrak{R}_{3}} \frac{\mathfrak{R}_{2}}{\mathfrak{R}_{1}+\mathfrak{R}_{2}} \\
=\frac{N_{L f 3} i_{c} \mathfrak{R}_{2}}{\mathfrak{R}_{1} \mathfrak{R}_{2}+\mathfrak{R}_{1} \mathfrak{R}_{3}+\mathfrak{R}_{2} \mathfrak{R}_{3}}, \\
\phi_{c b}=\frac{N_{L f 3} i_{c}\left(\mathfrak{R}_{1}+\mathfrak{R}_{2}\right)}{\mathfrak{R}_{1} \mathfrak{R}_{2}+\mathfrak{R}_{1} \mathfrak{R}_{3}+\mathfrak{R}_{2} \mathfrak{R}_{3}} \frac{\mathfrak{R}_{1}}{\mathfrak{R}_{1}+\mathfrak{R}_{2}} \\
=\frac{N_{L f 3} i_{c} \mathfrak{R}_{1}}{\mathfrak{R}_{1} \mathfrak{R}_{2}+\mathfrak{R}_{1} \mathfrak{R}_{3}+\mathfrak{R}_{2} \mathfrak{R}_{3}} .
\end{gathered}
$$
follows:

Furthermore, $V_{L f 1}, V_{L f 2}$, and $V_{L f 3}$ can be represented as

$$
\begin{aligned}
& V_{L f 1}=N_{L f 1} \frac{d}{d t}\left(\phi_{a}+\phi_{b a}+\phi_{c a}\right), \\
& V_{L f 2}=N_{L f 2} \frac{d}{d t}\left(\phi_{b}+\phi_{a b}+\phi_{c b}\right), \\
& V_{L f 3}=N_{L f 3} \frac{d}{d t}\left(\phi_{c}+\phi_{a c}+\phi_{b c}\right) .
\end{aligned}
$$

Based on the above formulas, the expression of integrated three-phase filter inductors with three magnetic limbs can be represented as follows:

$$
\left(\begin{array}{c}
V_{L f 1} \\
V_{L f 2} \\
V_{L f 3}
\end{array}\right)=\left(\begin{array}{lll}
L_{f 1} & M_{a b} & M_{a c} \\
M_{a b} & L_{f 2} & M_{b c} \\
M_{a c} & M_{b c} & L_{f 3}
\end{array}\right)\left(\begin{array}{c}
\frac{d i_{a}}{d t} \\
\frac{d i_{b}}{d t} \\
\frac{d i_{c}}{d t}
\end{array}\right)
$$

where $L_{f 1}, L_{f 2}$, and $L_{f 3}$ can be represented as follows:

$$
\begin{aligned}
L_{f 1} & =\frac{N_{L f 1}^{2}\left(\Re_{3}+\Re_{2}\right)}{\mathfrak{R}_{1} \mathfrak{R}_{2}+\mathfrak{R}_{1} \mathfrak{R}_{3}+\mathfrak{R}_{2} \mathfrak{R}_{3}}, \\
L_{f 2} & =\frac{N_{L f 2}^{2}\left(\mathfrak{R}_{1}+\mathfrak{R}_{3}\right)}{\mathfrak{R}_{1} \mathfrak{R}_{2}+\mathfrak{R}_{1} \mathfrak{R}_{3}+\mathfrak{R}_{2} \mathfrak{R}_{3}}, \\
L_{f 3} & =\frac{N_{L f 3}^{2}\left(\mathfrak{R}_{1}+\mathfrak{R}_{2}\right)}{\mathfrak{R}_{1} \mathfrak{R}_{2}+\mathfrak{R}_{1} \mathfrak{R}_{3}+\mathfrak{R}_{2} \mathfrak{R}_{3}} .
\end{aligned}
$$

$M_{a b}, M_{a c}$, and $M_{b c}$ are mutual inductors and can be represented as follows:

$$
M_{a b}=\frac{N_{L f 1} N_{L f 2} \Re_{3}}{\mathfrak{R}_{1} \mathfrak{R}_{2}+\mathfrak{R}_{1} \mathfrak{R}_{3}+\mathfrak{R}_{2} \mathfrak{R}_{3}},
$$




$$
\begin{aligned}
& M_{a c}=\frac{N_{L f 1} N_{L f 3} \Re_{2}}{\Re_{1} \Re_{2}+\Re_{1} \Re_{3}+\mathfrak{R}_{2} \mathfrak{R}_{3}}, \\
& M_{b c}=\frac{N_{L f 2} N_{L f 3} \mathfrak{R}_{1}}{\mathfrak{R}_{1} \mathfrak{R}_{2}+\mathfrak{R}_{1} \mathfrak{R}_{3}+\mathfrak{R}_{2} \mathfrak{R}_{3}} .
\end{aligned}
$$

Based on (43), it can be got that the three inductors couple with each other, and then the current ripple can be analyzed.

4.2. The Ripple Current of Three-Phase Integrated Filter Inductors with Three-Limb Magnetic Core. According to (43), $V_{L f 1}$, $V_{L f 2}$, and $V_{L f 3}$ can be described as follows:

$$
\begin{aligned}
& V_{L f 1}=V_{a}-e_{a}-e_{o}=L_{f 1} \frac{d i_{a}}{d t}+M_{a b} \frac{d i_{b}}{d t}+M_{a c} \frac{d i_{c}}{d t}, \\
& V_{L f 2}=V_{b}-e_{b}-e_{o}=L_{f 2} \frac{d i_{b}}{d t}+M_{a b} \frac{d i_{a}}{d t}+M_{b c} \frac{d i_{c}}{d t}, \\
& V_{L f 3}=V_{c}-e_{c}-e_{o}=L_{f 3} \frac{d i_{c}}{d t}+M_{b c} \frac{d i_{b}}{d t}+M_{a c} \frac{d i_{a}}{d t} .
\end{aligned}
$$

Based on (42) and (43), the self-inductors and mutual inductors are decided by magnetic resistors. The magnetic resistor can be got as follows:

$$
\mathfrak{R}_{i}=\frac{l_{g i}}{\mu_{0} A_{i}}, \quad i=1,2,3,
$$

where $l_{g i}$ and $A_{i}$, are respectively, the air gap and cross section area of $\mathfrak{R}_{0 i}$ and $\mu_{0}$ is air permeability.

Since one EE magnetic core is adopted in this paper, the cross section area of middle limb is twice than that of the other two limbs. Then, it makes the self-inductors and mutual inductors not the same. In order to make the three-phases balanced, the air gaps can be adjusted to make the magnetic resistors of three limbs the same. Therefore, it can be got that $l_{g 2}=2 l_{g 1}=2 l_{g 3}$. Furthermore, when $N_{L f 1}=N_{L f 2}=N_{L f 3}$, it can be got that $L_{f 1}=L_{f 2}=L_{f 3}=L_{f}$ and $M_{a b}=M_{a c}=$ $M_{b c}=M$. Therefore, (44) can be simplified as follows:

$$
\begin{aligned}
& V_{L f 1}=\frac{2 S_{a}-S_{b}-S_{c}}{3} V_{\text {in }}-e_{a}=L_{f} \frac{d i_{a}}{d t}+M \frac{d i_{b}}{d t}+M \frac{d i_{c}}{d t}, \\
& V_{L f 2}=\frac{2 S_{b}-S_{a}-S_{c}}{3} V_{\text {in }}-e_{b}=L_{f} \frac{d i_{b}}{d t}+M \frac{d i_{a}}{d t}+M \frac{d i_{c}}{d t}, \\
& V_{L f 3}=\frac{2 S_{c}-S_{a}-S_{b}}{3} V_{\text {in }}-e_{c}=L_{f} \frac{d i_{c}}{d t}+M \frac{d i_{b}}{d t}+M \frac{d i_{a}}{d t} .
\end{aligned}
$$

In order to analyze conveniently, take the one-phase ripple current $\Delta i_{a}$ of $L_{f 1}$, for example, to analyze, it can be got that

$$
\begin{aligned}
\Delta i_{a}= & \left(\frac{2 S_{a}-S_{b}-S_{c}}{3} V_{d c}-e_{a}-M \frac{d i_{b}}{d t}-M \frac{d i_{c}}{d t}\right) \\
& \times \frac{D_{\mathrm{on}} T}{L_{f 1}} .
\end{aligned}
$$

In three-phase system, the three-phase current $i_{a}, i_{b}$, and $i_{c}$ can be described as follows:

$$
\begin{gathered}
i_{a}=\sqrt{2} I_{m} \sin (\omega t), \\
i_{b}=\sqrt{2} I_{m} \sin \left(\omega t+\frac{2 \pi}{3}\right), \\
i_{c}=\sqrt{2} I_{m} \sin \left(\omega t-\frac{2 \pi}{3}\right),
\end{gathered}
$$

where $I_{m}$ is the effective value of current and $\omega$ is the line angular frequency.

According to (48), the ripple current $\Delta i_{a}$ can be simplified as follows:

$$
\begin{aligned}
\Delta i_{a}= & \left(\frac{2 S_{a}-S_{b}-S_{c}}{3} V_{d c}-e_{a}+\sqrt{2} M I_{m} \omega \cos (\omega t)\right) \\
& \times \frac{D_{\mathrm{on}} T}{L_{f 1}} .
\end{aligned}
$$

Compared with the ripple current of discrete inductors and integrated inductors with five limbs, it can be got that the ripple current with three limbs is influenced by additional $\sqrt{2} M I_{m} \omega \cos (\omega t)$. Therefore, mutual inductor $M$, current $I_{m}$, and angular frequency $\omega$ should be designed to fulfill the demand of current ripple. Then the value of $\sqrt{2} M I_{m} \omega \cos (\omega t)$ can be designed to be less than $10 \%\left(\left(2 S_{a}-\right.\right.$ $\left.\left.S_{b}-S_{c}\right) V_{\text {in }} / 3-e_{a}\right)$, and then the influence of $\sqrt{2} M I_{m} \omega \cos (\omega t)$ can be omitted. When the three-phase integrated inductors with three limbs operate in high frequency, large current, and large mutual inductor, the influence cannot be omitted and the harmonic cannot meet the demand. Therefore, when the value of $\sqrt{2} M I_{m} \omega \cos (\omega t)$ can be omitted, three-phase integrated inductors with three limbs can save more volume and achieve better power density.

\subsection{The Max Flux Density of Integrated Filter Inductors with} Three Magnetic Limbs. Since there are only three magnetic limbs in one magnetic core, the three-phase fluxes are coupled with each other. Take the first limb, for example, which is shown in Figure 7(a), the total flux $\phi_{1}$ of first limb consists of the flux $\phi_{a}$ generated by $L_{f 1}$ winding, the flux $\phi_{b a}$ generated by $L_{f 2}$ winding flows through the first limb, and flux $\phi_{c a}$ generated by $L_{f 3}$ winding flows through the first limb; then it can be got that

$$
\phi_{1}=\phi_{a}+\phi_{b a}+\phi_{c a} .
$$

The total flux can be further simplified as follows:

$$
\phi_{1}=\frac{1}{N_{L f 1}}\left(L_{f 1}-M\right) \sqrt{2} I_{m} \sin (\omega t) .
$$

Since the three-phase magnetic resistors and the number of turns of three-phase inductor are the same, it can be got 
that $\mathfrak{R}_{1}=\mathfrak{R}_{2}=\mathfrak{R}_{3}=\mathfrak{R}_{0}$, and $N_{L f 1}=N_{L f 2}=N_{L f 3}=N_{L f}$; then $L_{f 1}$ and $M$ can be described as follows:

$$
\begin{gathered}
L_{f 1}=\frac{2 N_{L f}^{2} u_{0} A_{1}}{3 l_{g 1}}, \\
M=\frac{N_{L f}^{2} u_{0} A_{1}}{3 l_{g 1}} .
\end{gathered}
$$

When $\phi_{1}$ achieves its $\max$ value $\phi_{1 \max }$, the max flux density $B_{1 \max }$ of second limb can be described as follows:

$$
B_{1 \max }=\frac{\phi_{1 \max }}{A_{1}}=\frac{N_{L f} u_{0} \sqrt{2} I_{m}}{3 l_{g 1}} .
$$

Also the max flux density $B_{2 \max }$ of second limb and the max flux density $B_{3 \max }$ of third limb can be described as follows:

$$
\begin{aligned}
& B_{2 \max }=\frac{N_{L f} u_{0} \sqrt{2} I_{m}}{3 l_{g 2}}, \\
& B_{3 \max }=\frac{N_{L f} u_{0} \sqrt{2} I_{m}}{3 l_{g 3}} .
\end{aligned}
$$

\section{The Comparison between Discrete Filter Inductors and Integrated Filter Inductors}

According to the above analyses, the comparison of the discrete filter inductors and integrated filter inductors is shown in Table 1. Then, based on the different demands of the PV inverter, different LC filter can be selected to fulfill the demands for the power density and the electrical performance.

\section{Experimental Results}

The parameters of three-phase inverter are shown as follows: the input voltage is $V_{\text {in }}=700 \mathrm{VDC}$, the three-phase output voltages are $e_{a}=e_{b}=e_{c}=220 \mathrm{VAC}$, the load frequency is $50 \mathrm{~Hz}$, load power is $3 \mathrm{~kW}$, three filter capacitors are $9 \mu \mathrm{F}$, the control method is SPWM, switching frequency is $15 \mathrm{kHz}$, the max duty cycle $D_{\text {on max }}$ is 0.85 , and the max value of every phase current is 7A. In this paper, three-phase discrete filter inductors, three-phase integrated filter inductors with five magnetic limbs, and three-phase integrated filter inductors with three magnetic limbs are, respectively, adopted to fulfill the demanded filter effect. In particular, the Three-phase integrated filter inductors can save more volume and achieve more power density.

6.1. The Volume Comparison of Three Kinds of Three-Phase Filter Inductors. In this paper, all the magnetic cores of three kinds of three-phase filter inductors are composed by power ferrite EE96/48/32 whose saturated flux density is $0.5 \mathrm{~T}$ and the cross section area of middle limb is $1024 \mathrm{~mm}^{2}$. The parameters of three kinds of filter inductors are shown in Table 2, the three-phase discrete filter inductors adopt three power ferrite EE96/48/32 cores, the three-phase integrated filter inductors with five limbs adopt two power ferrite EE96/48/32 cores, and the three-phase integrated filter inductors with three limbs adopt one power ferrite EE96/48/32 core. The self-inductance of three kinds of three filter inductors is $3.8 \mathrm{mH}$, and the number of turns is 80 . For the three-phase integrated filter inductors with three limbs; the cross section area of middle limb is twice than that of the other two limbs; then the air gap of middle limb is twice than that of the other two limbs to make the three-phases balanced. According to the analyses of flux density, it can be calculated that the max flux densities of three discrete filter inductors are $0.33 \mathrm{~T}$, the max flux densities of three middle limbs of integrated filter inductors with five limbs are $0.33 \mathrm{~T}$ and that of the other two limbs are zero, and the max flux densities of middle limb of integrated filter inductors with three limbs are $0.17 \mathrm{~T}$ and that of the other two limbs are $0.33 \mathrm{~T}$.

The magnetic cores of the discrete filter inductors, integrated filter inductors with five limbs and three limbs magnetics are shown in Figure 8. In Figure 8(a), three power ferrite EE96/48/32 cores are adopted in three-phase discrete filter inductors, and compared with the other two kinds of three-phase filter inductors, the volume of the threephase discrete filter inductors is the largest. In Figure 8(b), three power ferrite EE96/48/32 cores are adopted in threephase integrated filter inductors with five magnetic limbs; the middle three limbs have three-phase inductor's windings; the air gaps of the other two limbs can be adjusted to eliminate the three-phase flux coupling; therefore, this kind of threephase integrated filter inductors can achieve wild application and the volume is smaller than that of the three-phase discrete filter inductors. In Figure 8(c), one power ferrite EE96/48/32 cores is adopted in three-phase integrated filter inductors with three magnetic limbs, and compared with the other two kinds of three-phase filter inductors, all the three limbs have three-phase inductor's windings and the three-phase fluxes couple with each other, and then the application area is a little limited due to the coupling, but the advantage is that this kind of three-phase integrated filter inductors achieves the minimum volume.

6.2. The Filter Effect Comparison of Three Kinds of Three-Phase Filter Inductors. The SPWM control method is adopted in the three-phase inverter due to its simple and easy realizing, and it can be easily used to testify the three kinds of LC filters. The switching process of switch $Q_{1}$ and the control voltages $u_{\mathrm{Q} 1}$ and $u_{\mathrm{Q} 4}$ for the switch $Q_{1}$ and $Q_{4}$ are shown in Figure 9. The other control voltages are similar to $u_{\mathrm{O} 1}$ and $u_{\mathrm{Q} 4}$.

Furthermore, in order to testify the filter effects of the three kinds of three-phase filter inductors, the current THD (total harmonic distortion) of three kinds of three-phase filter inductors is compared. The three-phase load currents of three-phase discrete filter inductors are shown in Figure 10, and the THD of A phase, B phase, and C phase is, respectively, $4.5 \%, 4.7 \%$, and $4.1 \%$, and all can achieve the demand. The three-phase load currents of three-phase integrated filter inductors with five limbs are shown in Figure 11, and the THD of A phase, B phase, and C phase is, respectively, 4.4\%, $4.6 \%$, 
TABLE 1: The comparison of the discrete filter inductors and integrated filter inductors.

\begin{tabular}{lcccc}
\hline & $\begin{array}{c}\text { The volume of } \\
\text { magnetic core }\end{array}$ & The cost & The three phase coupling & $\begin{array}{c}\text { Current ripple influenced by the } \\
\text { other two phases }\end{array}$ \\
\hline $\begin{array}{l}\text { Discrete filter inductor } \\
\text { Integrated filter inductor (five limbs) }\end{array}$ & Large & Large & Decoupling & Not influenced \\
Integrated filter inductor (three limbs) & Small & Medium & Can be adjusted to decoupling & Can be adjusted to not influenced \\
\hline
\end{tabular}

TABLE 2: The comparison of the discrete magnetics, five-limb magnetics, and three-limb magnetics.

\begin{tabular}{|c|c|c|c|c|c|c|}
\hline & $\begin{array}{l}\text { The number of } \\
\text { magnetic core }\end{array}$ & $\begin{array}{l}\text { The cross section } \\
\text { area of middle limb }\end{array}$ & Air gap distribution & Inductance & $\begin{array}{c}\text { The number } \\
\text { of turns }\end{array}$ & $\begin{array}{l}\text { The max flux } \\
\text { density }\end{array}$ \\
\hline $\begin{array}{l}\text { Discrete filter } \\
\text { inductor }\end{array}$ & Three EE96/48/32 & $1024 \mathrm{~mm}^{2}$ & $\begin{array}{l}\text { The air gap of middle } \\
\text { limb is } 2.0 \mathrm{~mm} \text {; the air } \\
\text { gaps of the other limbs } \\
\text { are zero }\end{array}$ & $\begin{array}{l}\text { Self-inductance is } \\
3.8 \mathrm{mH}\end{array}$ & 80 & $0.33 \mathrm{~T}$ \\
\hline $\begin{array}{l}\text { Integrated filter } \\
\text { inductor (five limbs) }\end{array}$ & Two EE96/48/32 & $1024 \mathrm{~mm}^{2}$ & $\begin{array}{l}\text { The air gaps of middle } \\
\text { three limbs are } 2.0 \mathrm{~mm} \text {; } \\
\text { the air gaps of the other } \\
\text { two limbs are zero }\end{array}$ & $\begin{array}{l}\text { Self-inductance is } \\
3.8 \mathrm{mH}\end{array}$ & 80 & $0.33 \mathrm{~T}$ \\
\hline $\begin{array}{l}\text { Integrated filter } \\
\text { inductor (three limbs) }\end{array}$ & One EE96/48/32 & $1024 \mathrm{~mm}^{2}$ & $\begin{array}{l}\text { The air gap of middle } \\
\text { limb is } 1.4 \mathrm{~mm} \text {; the air } \\
\text { gaps of the other limbs } \\
\text { are } 0.7 \mathrm{~mm}\end{array}$ & $\begin{array}{c}\text { Self-inductance is } \\
3.8 \mathrm{mH} \text {; mutual } \\
\text { inductance is } \\
1.9 \mathrm{mH}\end{array}$ & 80 & $\begin{array}{c}\text { Middle limb is } \\
0.17 \mathrm{~T} \text {; the } \\
\text { other two } \\
\text { limbs are } 0.33 \mathrm{~T}\end{array}$ \\
\hline
\end{tabular}

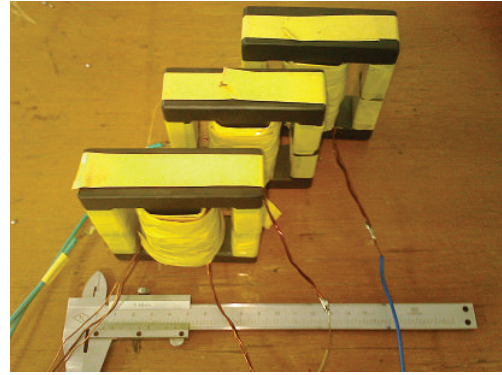

(a)

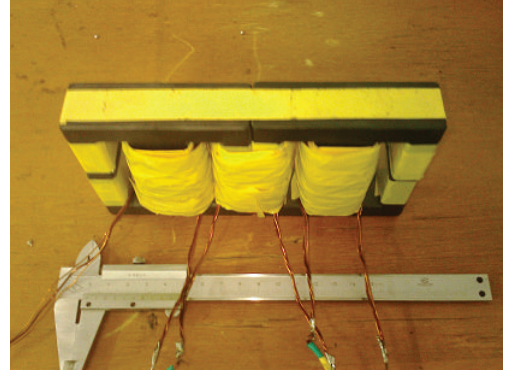

(b)

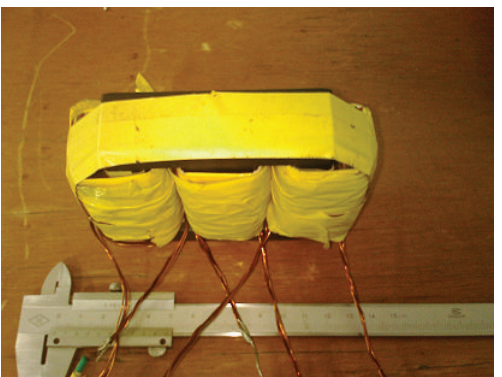

(c)

FIGURE 8: The comparison of discrete magnetics, five-limb magnetics, and three-limb magnetics: (a) discrete magnetic cores, (b) integrated magnetic core with five limbs, and (c) integrated magnetic core with three limbs.

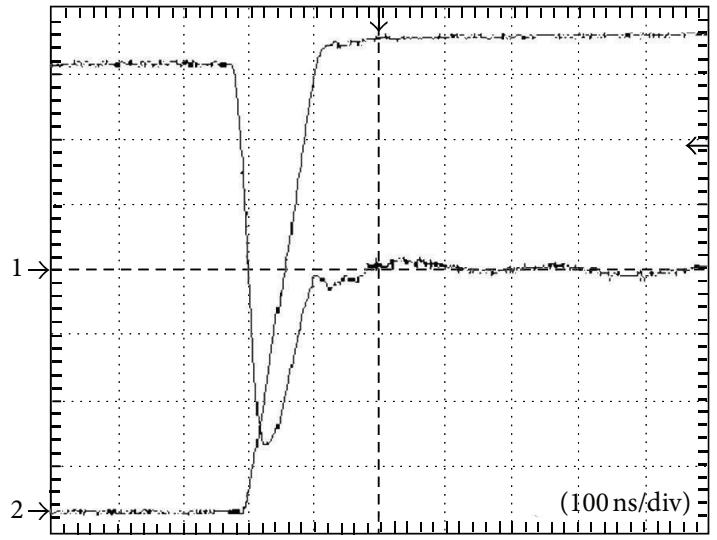

(a)

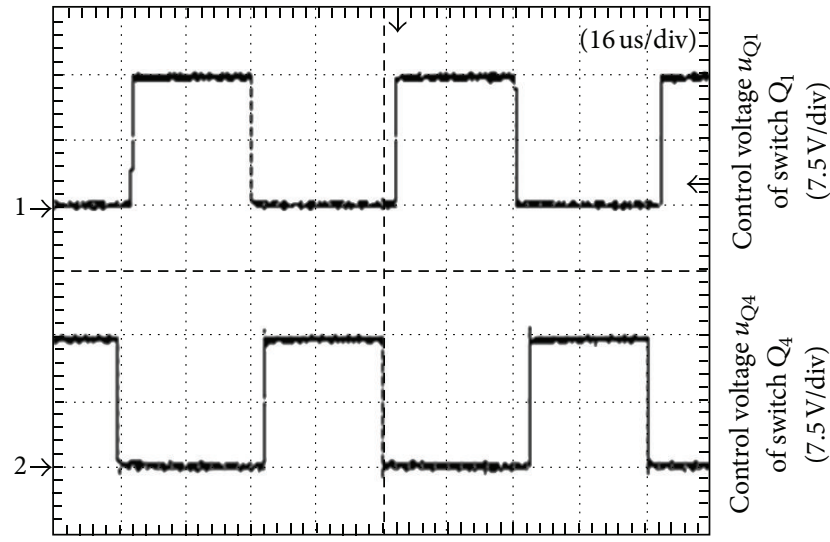

(b)

FIGURE 9: The waveforms of switching process and control voltages: (a) the switching process of switch $Q_{1}$, (b) the control voltages for the switch $Q_{1}$ and $Q_{4}$. The voltage measured in $\mathrm{CH} 2$ by the voltage transformer; the proportion is $1 \mathrm{~V}=100 \mathrm{~V}$; in $\mathrm{CH} 1,1 \mathrm{~V}=1 \mathrm{~A}$; the time per DIV is $100 \mathrm{~ns}$. In $\mathrm{CH} 1$, the voltage per DIV is $7.5 \mathrm{~V}$; in $\mathrm{CH} 2$, the voltage per DIV is $7.5 \mathrm{~V}$; the time per DIV is 16.6 us. 


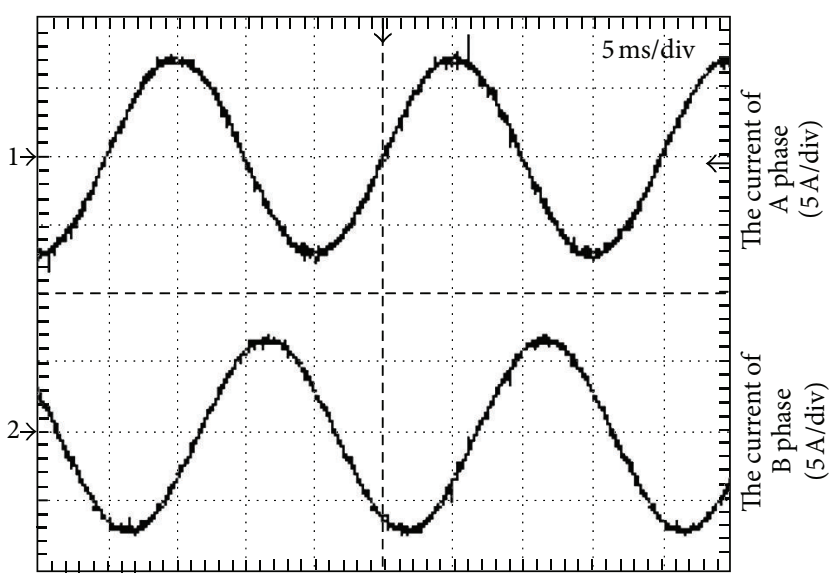

(a)

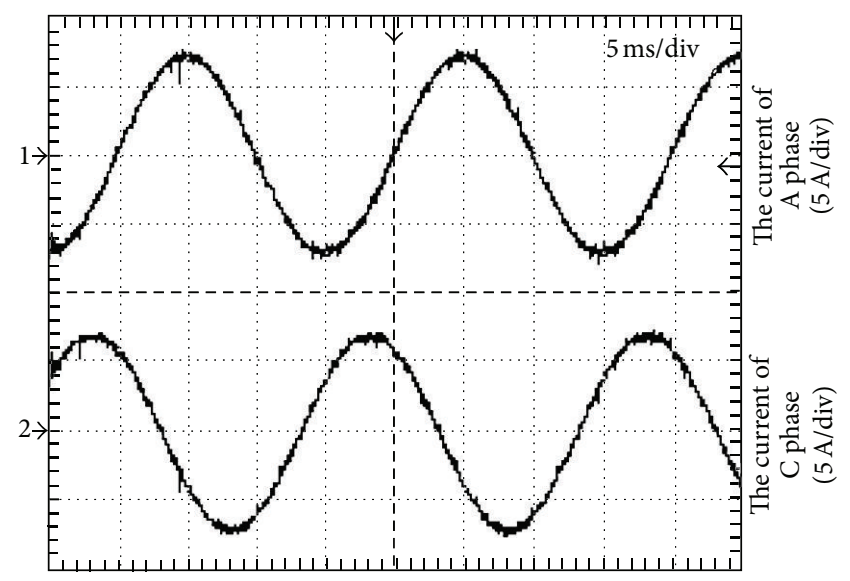

(b)

FIGURE 10: The three-phase load current with discrete filter inductor: (a) the current of A phase and B phase, (b) the current of A phase and $\mathrm{C}$ phase. In $\mathrm{CH} 1$, the current comes from the current transformer and the proportion is $1 \mathrm{~V}=5 \mathrm{~A}$; it means that the current per DIV is $5 \mathrm{~A}$; in $\mathrm{CH} 2$, the current per DIV is $5 \mathrm{~A}$; the time per DIV is $5 \mathrm{~ms}$.

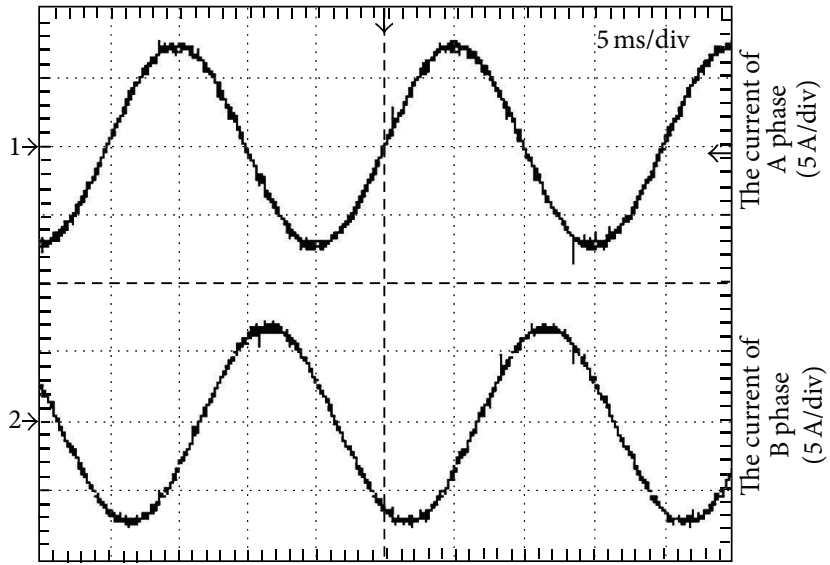

(a)

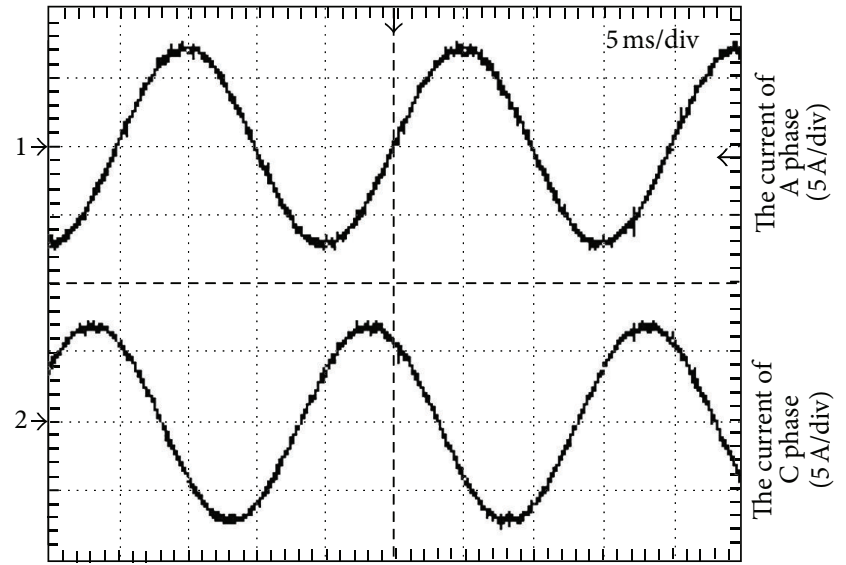

(b)

FIGURE 11: The three-phase load current with integrated filter inductor with five limbs: (a) the current of A phase and B phase, (b) the current of $\mathrm{A}$ phase and $\mathrm{C}$ phase. In $\mathrm{CH} 1$, the current comes from the current transformer and the proportion is $1 \mathrm{~V}=5 \mathrm{~A}$; it means that the current per DIV is $5 \mathrm{~A}$; in $\mathrm{CH} 2$, the current per DIV is $5 \mathrm{~A}$; the time per DIV is $5 \mathrm{~ms}$.

and $4.4 \%$, and all can achieve the demand. The three-phase load currents of three-phase integrated filter inductors with three limbs are shown in Figure 12, and the THD of A phase, B phase, and C phase is, respectively, $4.5 \%, 4.4 \%$, and $4.1 \%$, and all can achieve the demand. Therefore, all three kinds of threephase filter inductors can fulfill the demand of the current THD. For the low and medium power application, the threephase coupling in the integrated filter inductors with three limbs can be omitted, and then the integrated filter inductors with three limbs can be chosen due to the minimum volume. Take A phase current of three-phase integrated filter inductors with three limbs, for example, based on formula (42), $\sqrt{2} M I_{m} \omega \cos (\omega t)$ is caused by coupling, and its max value is $\sqrt{2} M I_{m} \omega$. In this paper, $M=1.9 \mathrm{mH}, I_{m}=5 \mathrm{~A}$, $\omega=2 \pi f=314$, and then it can be calculated that $\sqrt{2} M I_{m} \omega=$ $4.2 \mathrm{~V}$. Compared with $V_{\text {in }}(700 \mathrm{VDC})$ and $e_{a} s(220 \mathrm{VAC})$, the coupling voltage $\sqrt{2} M I_{m} \omega=4.2 \mathrm{~V}$ is very small and can be omitted. But for the large power application, load current $I_{m}$ is large and the coupling cannot be omitted; then it is difficult to achieve the ideal filter effect. Therefore, for the large power application, the integrated filter inductors with five limbs can be chosen. The coupling of the integrated filter inductors with five limbs can be eliminated by adjusting the air gap of two side limbs, and then the filter effect is the same as the discrete filter inductors and the volume is less than the discrete filter inductors.

\section{Conclusion}

In this paper, the comparison analyses of three-phase discrete filter inductors and two kinds of three-phase integrated filter inductors in three-phase PV inverter are proposed. The experiment results show that the volumes of three-phase integrated filter inductors are reduced obviously. Compared 


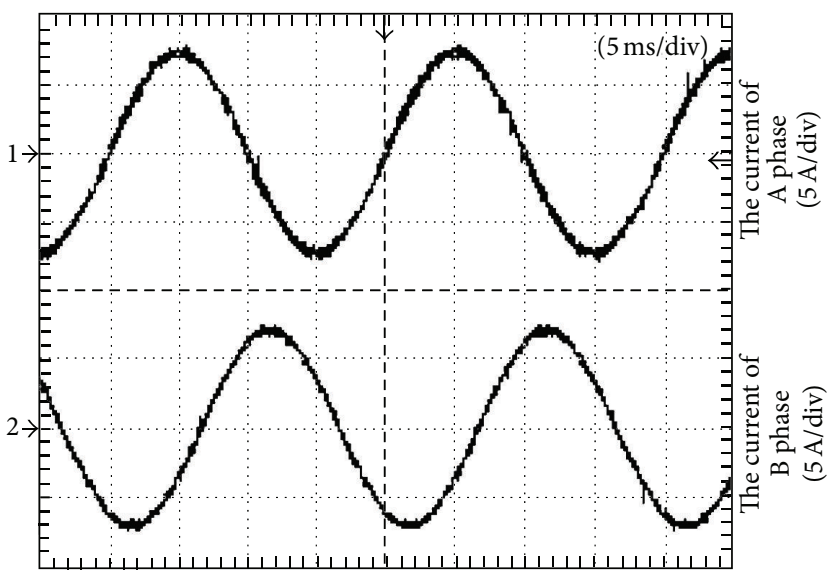

(a)

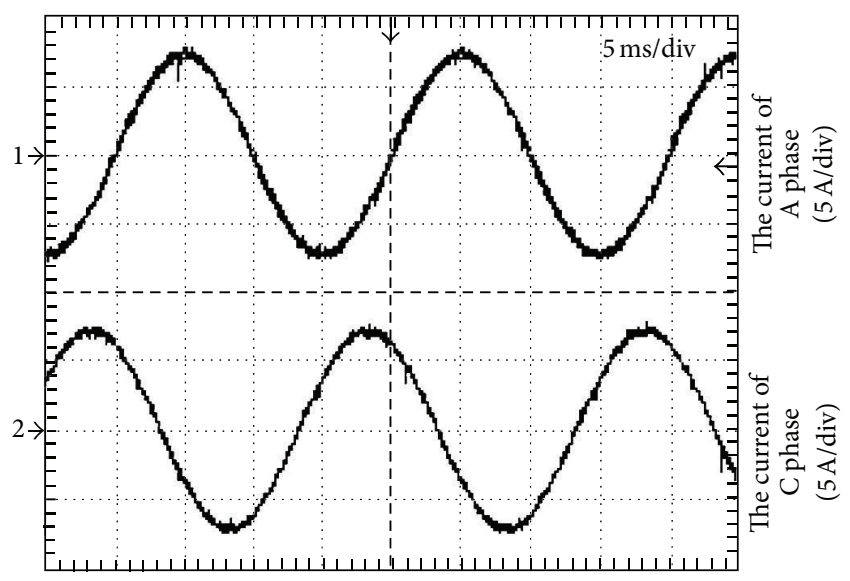

(b)

FIGURE 12: The three-phase load current with integrated filter inductor with three limbs: (a) the current of A phase and B phase, (b) the current of A phase and $\mathrm{C}$ phase. In $\mathrm{CH} 1$, the current comes from the current transformer and the proportion is $1 \mathrm{~V}=5 \mathrm{~A}$; it means that the current per DIV is $5 \mathrm{~A}$; in $\mathrm{CH} 2$, the current per DIV is $5 \mathrm{~A}$; the time per DIV is $5 \mathrm{~ms}$.

with three-phase discrete filter inductors, the volumes of the five-limb integrated filter inductors are reduced third, the three-limb integrated filter inductors are reduced two-thirds, and the filter effects of three kinds of filter inductors are almost the same; all can achieve the good filter effect. Based on the different demands of the PV inverter, different LC filter can be selected to fulfill the demands for the power density and the electrical performance. The analyzed method also can be used in three-phase LCL filter.

\section{Acknowledgments}

This work was supported in part by the National Natural Science Foundation of China (51277121), in part by the National Natural Science Foundation of China (U1204515), in part by the Key Subject Research Program of Education Commission of Shanghai (J51901), in part by the Shanghai Young College Teacher Training and Finance Assistance Scheme (SDJ12001), in part by the Key Cultivation Program of Shanghai Dianji University (12C103), and in part by the Starting Research Fund of Shanghai Dianji University (11C418).

\section{References}

[1] S. B. Kjaer, J. K. Pedersen, and F. Blaabjerg, "Power inverter topologies for photovoltaic modules: a review," in Proceedings of the 37th Conference Record of the Industry Applications (IAS'02), pp. 782-788, 2002.

[2] M. Meinhardt and G. Cramer, "Past, present and future of grid connected photovoltaic- and hybrid-power-systems," in Proceedings of the Power Engineering Society Summer Meeting, vol. 2, pp. 1283-1288, July 2000.

[3] Q. Li and P. Wolfs, "A review of the single phase photovoltaic module integrated converter topologies with three different DC link configurations," IEEE Transactions on Power Electronics, vol. 23, no. 3, pp. 1320-1333, 2008.

[4] S. B. Kjaer and F. Blaabjerg, "Design optimization of a single phase inverter for photovoltaic applications," in Proceedings of the Power Electronics Specialist Conference (PESC'03), pp. 11831190, 2003.

[5] E. Figueres, G. Garcerá, J. Sandia, F. González-Espín, and J. C. Rubio, "Sensitivity study of the dynamics of three-phase photovoltaic inverters with an LCL grid filter," IEEE Transactions on Industrial Electronics, vol. 56, no. 3, pp. 706-717, 2009.

[6] M. C. Cavalcanti, K. C. de Oliveira, A. M. de Farias, F. A. S. Neves, G. M. S. Azevedo, and F. C. Camboim, "Modulation techniques to eliminate leakage currents in transformerless threephase photovoltaic systems," IEEE Transactions on Industrial Electronics, vol. 57, no. 4, pp. 1360-1368, 2010.

[7] S. M. Moosavian, N. A. Rahim, and J. Selvaraj, "Photovoltaic power generation: a review," in Proceedings of the 1st Conference on Clean Energy and Technology (CET '11), pp. 359-363, June 2011.

[8] H. Kim and K.-H. Kim, "Filter design for grid connected PV inverters," in Proceedings of the IEEE International Conference on Sustainable Energy Technologies (ICSET '08), pp. 1070-1075, November 2008.

[9] Y. Lang, D. Xu, S. R. Hadianamrei, and H. Ma, "A novel design method of LCL type utility interface for three-phase voltage source rectifier," in Proceedings of the Power Electronics Specialists Conference (PESC '05), pp. 313-317, 2005.

[10] H. Cha and S. Lee, "Design and implementation of photovoltaic power conditioning system using a current based maximum power point tracking," in Proceedings of the IEEE Industry Applications Society Annual Meeting (IAS '08), pp. 1-5, October 2008.

[11] M. Liserre, F. Blaabjerg, and S. Hansen, "Design and control of an LCL-filter-based three-phase active rectifier," IEEE Transactions on Industry Applications, vol. 41, no. 5, pp. 1281-1291, 2005.

[12] L. A. Serpa, S. Ponnaluri, P. M. Barbosa, and J. W. Kolar, "A modified direct power control strategy allowing the connection of three-phase inverters to the grid through LCL filters," IEEE Transactions on Industry Applications, vol. 43, no. 5, pp. 13881400, 2007.

[13] E. Twining and D. G. Holmes, "Grid current regulation of a three-phase voltage source inverter with an LCL input filter," IEEE Transactions on Power Electronics, vol. 18, no. 3, pp. 888$895,2003$. 
[14] M. Liserre, A. Dell'Aquila, and F. Blaabjerg, "Genetic algorithmbased design of the active damping for an LCL-filter three-phase active rectifier," IEEE Transactions on Power Electronics, vol. 19, no. 1, pp. 76-86, 2004.

[15] M. Liserre, R. Teodorescu, and F. Blaabjerg, "Stability of photovoltaic and wind turbine grid-connected inverters for a large set of grid impedance values," IEEE Transactions on Power Electronics, vol. 21, no. 1, pp. 263-271, 2006.

[16] M. Malinowski and S. Bernet, "A simple voltage sensorless active damping scheme for three-phase PWM converters with an LCL filter," IEEE Transactions on Industrial Electronics, vol. 55, no. 4, pp. 1876-1880, 2008.

[17] Y. Jiang, Z. Chen, and J. Pan, "Zero-voltage switching phase shift full-bridge step-up converter with integrated magnetic structure," IET Power Electronics, vol. 3, no. 5, pp. 732-739, 2010.

[18] Q. Li and P. Wolfs, "A current fed two-inductor boost converter with an integrated magnetic structure and passive lossless snubbers for photovoltaic module integrated converter applications," IEEE Transactions on Power Electronics, vol. 22, no. 1, pp. 309321, 2007.

[19] R. C. Variath, M. A. E. Andersen, O. N. Nielsen, and A. Hyldgård, "A review of module inverter topologies suitable for photovoltaic systems," in Proceedings of the 9th International Power and Energy Conference (IPEC '10), pp. 310-316, October 2010.

[20] J.-P. Lee, B.-D. Min, T.-J. Kim, D.-W. Yoo, and J.-Y. Yoo, "A novel topology for photovoltaic DC/DC full-bridge converter with flat efficiency under wide PV module voltage and load range," IEEE Transactions on Industrial Electronics, vol. 55, no. 7, pp. 2602-2609, 2008.

[21] M. Fortunato, A. Giustiniani, G. Petrone, G. Spagnuolo, and M. Vitelli, "Maximum power point tracking in a one-cyclecontrolled single-stage photovoltaic inverter," IEEE Transactions on Industrial Electronics, vol. 55, no. 7, pp. 2684-2693, 2008. 

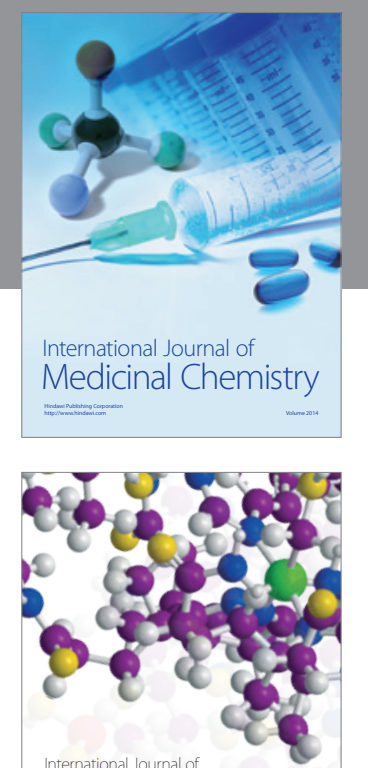

\section{Carbohydrate} Chemistry

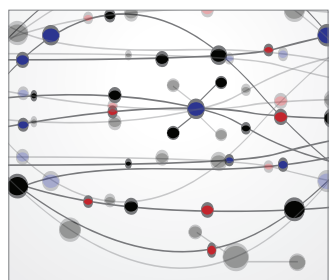

The Scientific World Journal
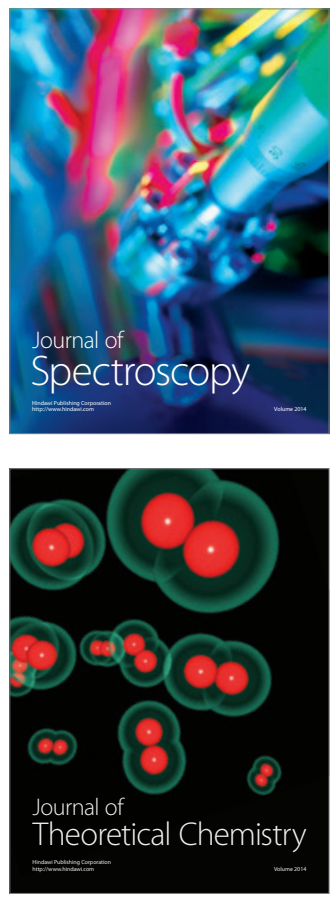
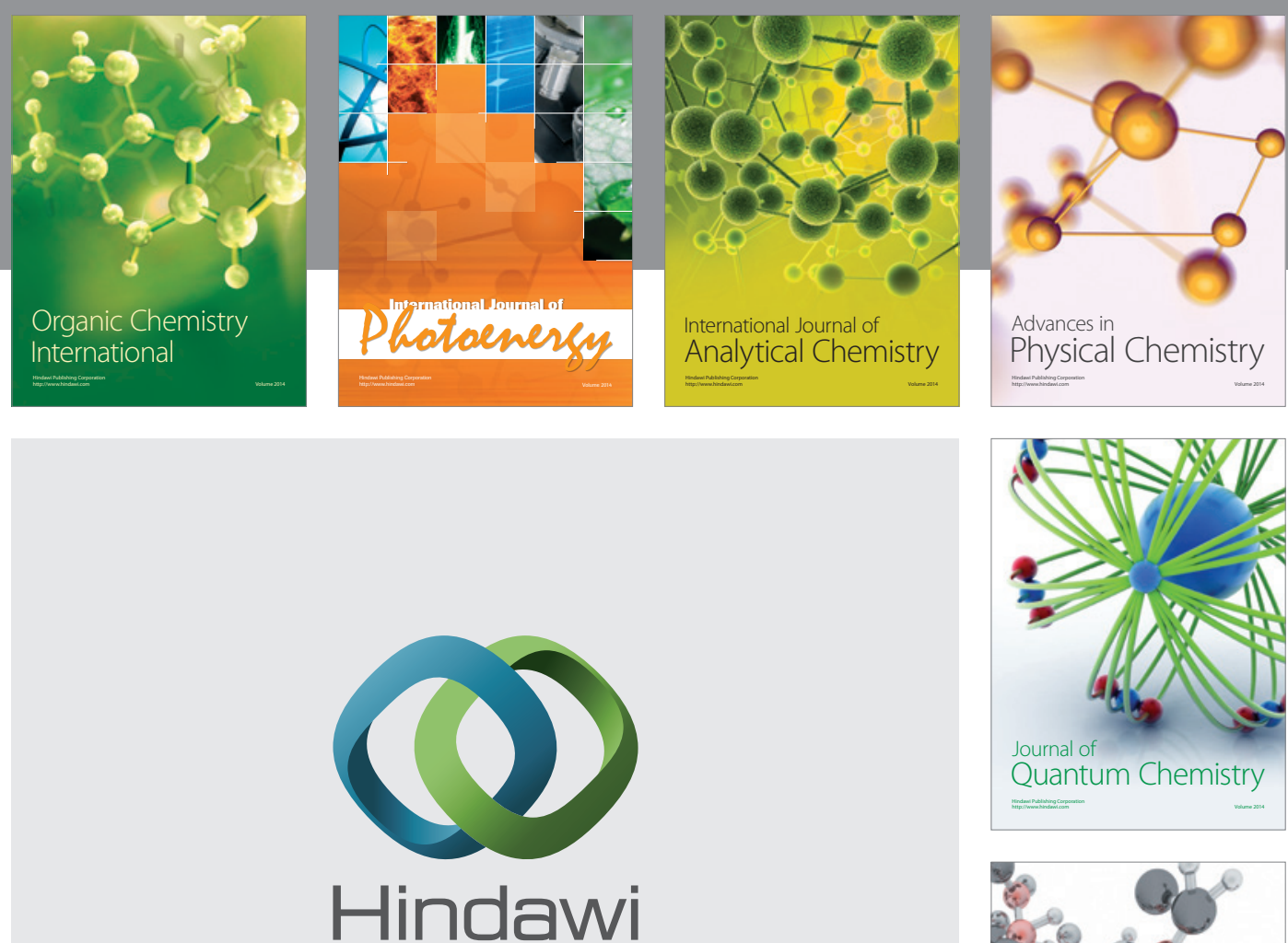

Submit your manuscripts at

http://www.hindawi.com

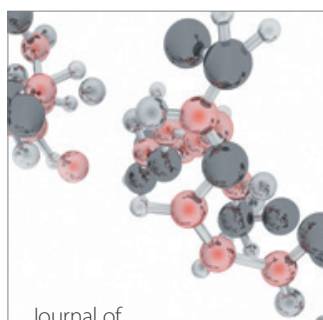

Analytical Methods

in Chemistry

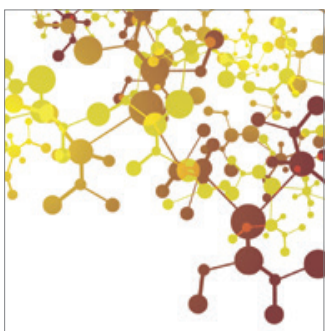

Journal of

Applied Chemistry

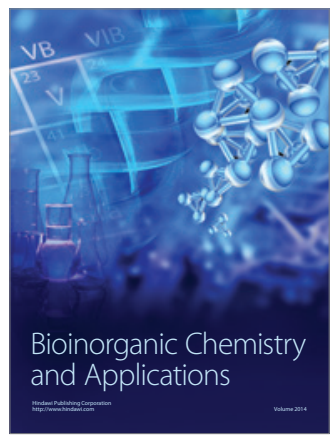

Inorganic Chemistry
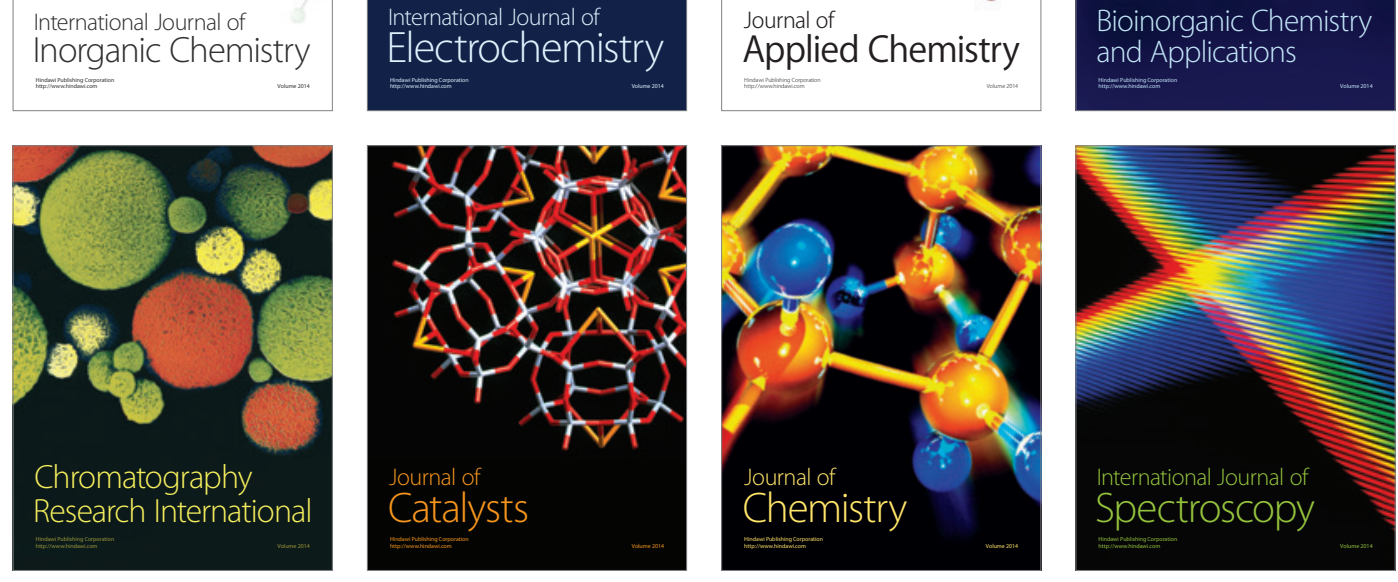